Research Article

\title{
Temperature Adaptability of Asphalt Pavement to High Temperatures and Significant Temperature Differences
}

\author{
Xueying Zhao ${ }^{D},{ }^{1}$ Aiqin Shen, ${ }^{1}$ and Baofu $\mathrm{Ma}^{2}$ \\ ${ }^{1}$ Key Laboratory of Highway Engineering in Special Region of Ministry of Education, Chang'an University, \\ Middle-Section of Nan'er Huan Road, Xi'an, Shaanxi 710064, China \\ ${ }^{2}$ China Communications Construction Company Highway Consultants Co., Ltd., Beijing, China
}

Correspondence should be addressed to Xueying Zhao; 419258621@qq.com

Received 25 January 2018; Revised 17 April 2018; Accepted 23 April 2018; Published 8 July 2018

Academic Editor: Kaveh Edalati

Copyright (c) 2018 Xueying Zhao et al. This is an open access article distributed under the Creative Commons Attribution License, which permits unrestricted use, distribution, and reproduction in any medium, provided the original work is properly cited.

\begin{abstract}
Temperature adaptability of asphalt pavements is very important, due to their potential influence on pavement structure design, particularly in areas that experience significant temperature differences. In this paper, a finite element (FE) model was developed, and Turpan-Xiaocao Lake Highway in southern Xinjiang was taken as a case study engineering, which tends to experience this adverse environmental condition (temperature difference: $25.5^{\circ} \mathrm{C}$; July 14, 2008). In this model, the generalized Kelvin model and the Burgers model were used. The time-dependent tire pressure was considered. To guide pavement structure design and control pavement distresses in this area, seven alternative pavement structures were selected to simulate and analyze pavement temperature fields and the mechanical responses. It was observed that the influence of air temperature had the greatest impact on Str1 , possibly due to the thinnest asphalt course. Moreover, when rutting depth, maximum shear stress of the asphalt course, deflection on the pavement surface, and compressive strains at the subgrade top surface were taken as the evaluation indices, the adaptability of asphalt pavements using compound base courses had obvious advantage due to their strong absorption and reflection of load impact. The adaptability of seven structures analyzed in this paper decreased in the following order: Str-5 $>$ Str$6>$ Str- $4>$ Str- $2>$ Str-m $>$ Str-1 $>$ Str-3. In addition, it broke the traditional view that asphalt pavement with a flexible base had the poor ability on rutting resistance. Besides, it also suggests that when the thickness of asphalt courses was equivalent, increasing the thickness of chemical-treated base courses would help with the deformation resistance, and vice versa.
\end{abstract}

\section{Introduction}

Asphalt mixtures are sensitive to temperature, and therefore, significant temperature differences are always adverse factors to asphalt pavement construction and rehabilitation. However, they are not considered essential in asphalt pavement design in such areas, which is a fundamental flaw in the theoretical system of pavement design in China. Moreover, when climatic characteristics of significant temperature differences and high temperatures are experienced simultaneously, pavement structures will be subjected to more adverse conditions, and they are very likely to result in early asphalt pavement distresses, which will negatively influence pavement performances and durability. For example, Xinjiang Uyghur Autonomous Region in China (referred to as Xinjiang), in its southern part, shows a large daily and annual temperature difference and continuous high air temperatures. In the high-temperature season, the daily temperature difference could be more than $20^{\circ} \mathrm{C}$ and the maximum temperature could be up to $47.7^{\circ} \mathrm{C}$ [1]. In this area, influenced by high temperatures and significant temperature differences, asphalt pavement distresses, such as rutting and shoving, are very serious. In national highway no. 314, Akesu-Kashgar Section, the average rutting depth was $10.5 \mathrm{~mm}$, and the maximum rutting depth could be up to $17 \mathrm{~mm}$.

When analyzing the effects of significant temperature differences and high temperatures on asphalt pavements, the following two aspects have been primarily focused: pavement temperature fields and induced mechanical responses of pavements. In these two aspects, the former was the foundation for calculating and evaluating thermal effects on asphalt pavement structures, and the latter was the direct 
reflection of the adaptability of pavement structures to significant temperature differences and high temperatures.

For the analysis of pavement temperature fields, there are two approaches [2]: the theoretical analysis method and the statistical analysis method. The first one was to calculate asphalt pavement temperature fields through heat transfer theory based on climatological data. The second one was to establish the relationship between pavement temperature fields and environmental conditions, such as air temperature and radiation, through statistical regression, based on pavement temperatures and meteorological data acquired from field equipment.

Since it was studied thoroughly in the 1950s, research concerning pavement temperature fields can be divided into three stages based on objectives, contents, and methods. The first stage extended from the 1950s to the 1990s, and research primarily focused on variation patterns and the distribution in pavement temperatures [2-6]. However, due to limited experimental conditions and field equipment, data acquired in this period were insufficient and their representativeness was not sufficiently strong. Thus, the theoretical analysis method was selected in most cases. Research results were primarily limited to theoretical analysis based on the one-dimensional heat conduction model and rarely applied in practice. The second stage occurred during the 1990s, and in this period, Superpave was proposed and studied thoroughly. It was required that asphalt binder should satisfy certain performance metrics under maximum and minimum design temperatures, which was a milestone in the study of pavement temperature. However, this approach (the Performance Grade) received considerable criticisms due to its inability to correctly characterize asphalt binder [7-10]. There has been a deficiency of the correlation between the high-temperature parameter $\left(G^{*} / \sin \delta\right)$ and asphalt mixture or pavement performance, especially modified asphalt mixture [7]. Moreover, a considerable amount of pavement temperature and meteorological data were collected in the US and Canada, and a database was established, which filled the gap in the early stage about the limited data acquired. In this stage, the objective was considerably clear, which was to determine the most extreme temperature condition that an asphalt pavement could withstand in its lifetime. The third stage indicated the 21st century. Research on the theoretical analysis method and the statistical analysis method has both made rapid and brilliant progress. Due to the database established in the 1990s, temperature prediction models were improved and perfected [11-14]. In addition, temperature variation was simulated in a short period such as 1 day or $1 \mathrm{~h}$, typically through the finiteelement (FE) method [15-17].

However, in spite of the large database and the theoretical calculation at present, there were still two problems: The first was that the adaptability of prediction models and theoretical analysis was questionable and probably limited because conditions of significant temperature differences and high temperatures were special and rarely reconstructed in other areas. The second was that the influence of the structure and materials could not be reflected in the proposed prediction models, which had limited guidance for pavement design in such areas. In this case, compared with the statistical analysis method, the theoretical analysis method was recommended; however, the particular condition of significant temperature differences and high temperatures needs detailed analysis.

In addition, for the simulation of pavement mechanical responses, research could be divided into two categories approximately: the mechanical property of asphalt mixtures under different temperatures [18-20], that is, through the destructive test under a specific temperature, and the mechanical simulation of asphalt pavements under the ambient temperature $[16,21-24]$, that is, through the grounded methodology for the Chinese pavement structure design or FE analysis.

The key for accurate prediction of pavement mechanics is to simulate pavement responses more realistically in terms of loading conditions, material characterization, and environmental situations. However, in the present theoretical system of pavement design in China, the multilayered elastic theory is adopted, which has a number of limitations that result in inaccurate mechanical responses, including the assumption of ambient temperature, constant traffic loads, and linear elastic analysis of asphalt concrete and base materials. By contrast, the FE method simulates pavement responses more accurately.

However, at present, there are fatal deficiencies in the simulation of high-temperature climates experiencing significant temperature differences because this climatic characteristic is not a place where sufficient emphasis is on. On the threshold, in current research, such environmental conditions could not be simulated realistically. In the multilayered elastic theory, the ambient temperature was assumed to be $20^{\circ} \mathrm{C}$. Secondly, asphalt mixture exhibits both viscoelasticity and plasticity. In the case of significant temperature differences and high temperatures, it is subjected to the transfer from the dominating viscoelasticity towards the dominating plasticity. As for asphalt pavements, when traffic loads are applied repeatedly, viscoelastic deformation accumulated in the day time would transform into a plastic one. However, in the FE analysis at present, it simply coupled the temperature and traffic loads, and this material characterization of viscoelasticity and plasticity transformation commutatively could not be represented.

Therefore, to guide pavement design in areas experiencing significant temperature differences and high temperatures, it is of vital importance to study the adaptability of asphalt pavement specifically. Located in Central Asia and Northwest China, far from the sea, southern Xinjiang is a typical area of significant temperature differences and high temperatures. In this paper, the Turpan-Xiaocao Lake Highway in southern Xinjiang was taken as a case study engineering. Seven alternative asphalt pavement structures commonly used in China and southern Xinjiang were selected, and their temperature fields and mechanical responses were simulated and analyzed through the FE program (ANSYS).

This paper is organized as follows:

(1) Introduction of the climatic characteristics in southern Xinjiang and areas along the Turpan-Xiaocao Lake Highway (referred to as the Turpan-Xiaocao Lake area), which is a typical representation of an area 


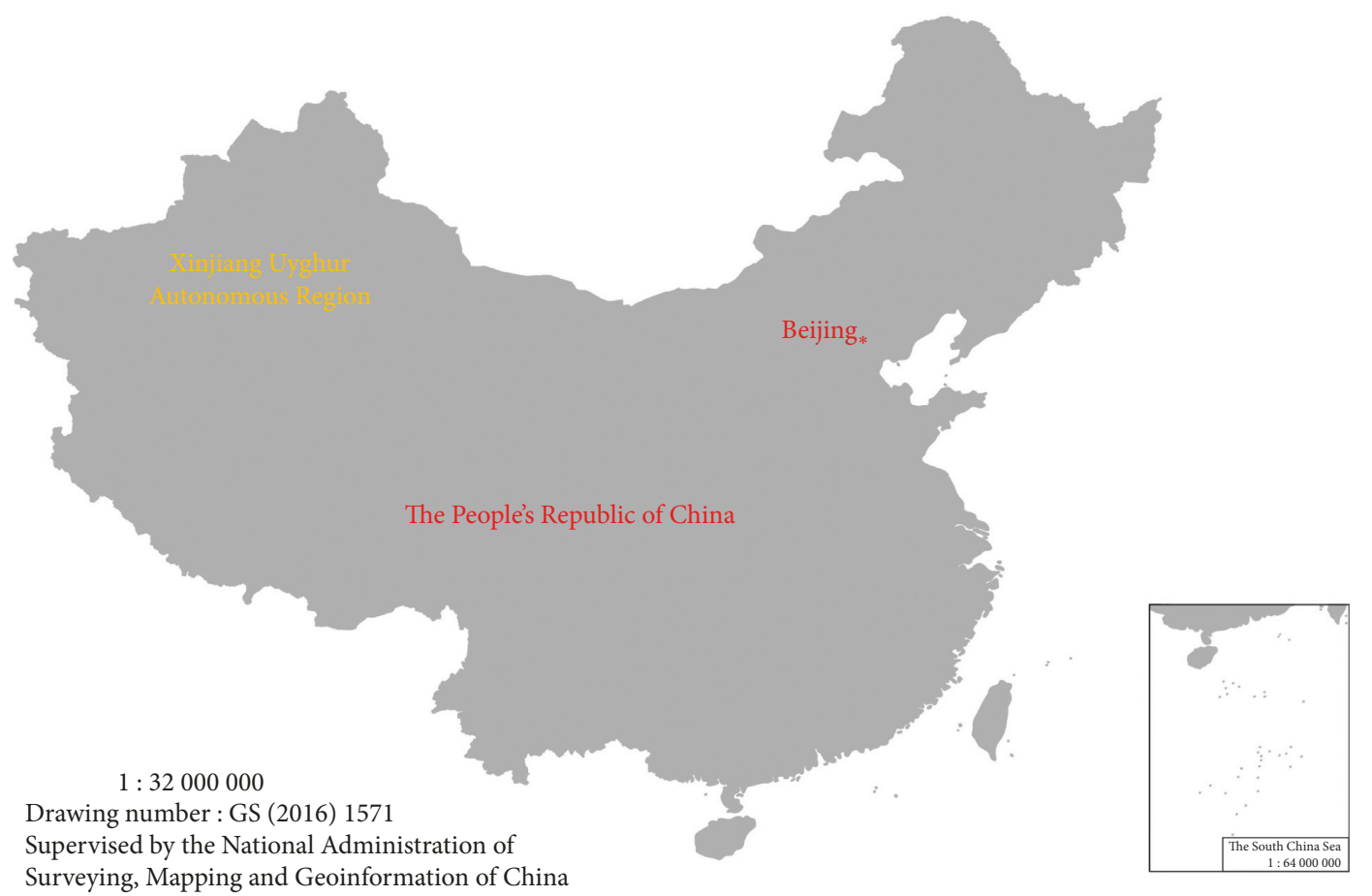

Figure 1: Location of Xinjiang. Source: website of the Chinese National Administration of Surveying, Mapping and Geoinformation.

experiencing large temperature differences and high temperatures

(2) Investigation of common pavement distresses in southern Xinjiang

(3) Proposed FE models and thermal and mechanical boundary conditions for pavements

(4) Material characterization and the constitutive model of asphalt mixture

(5) Simulation results of pavement temperature fields and mechanical responses of asphalt pavements subjected to significant temperature differences and high temperatures

(6) Conclusions and suggestions for future pavement design for areas experiencing large temperature differences and high temperatures.

\section{Climatic Characteristics of the Turpan- Xiaocao Lake Area}

According to geographical division, Xinjiang is located in Central Asia (shown in Figure 1), and southern Xinjiang is composed of southern Akesu, Turpan, Bayin'gholin, Khotan, Kashgar, and so on. It experiences continuous high temperatures, abundant sunshine, significant temperature differences, and infrequent precipitation. The location of the Turpan-Xiaocao Lake Highway is shown in Figure 2.

2.1. Continuous High Temperatures and Significant Temperature Differences. In southern Xinjiang, summer lasts for 4-5 months, and the climatic characteristics include significant temperature differences, abundant sunshine, scorching heat, and a long high-temperature season. The annual duration of sunshine could be up to 3000-3500 hours, and the average annual radiation is approximately $6000 \mathrm{MJ} / \mathrm{m}^{2}$ [25]. From Figures 3(a)-3(c), the condition of continuous significant temperature differences and high temperatures in southern Xinjiang and the Turpan-Xiaocao Lake area could be seen, especially in Turpan.

From Figure 3, it could be found that the maximum air temperatures in Turpan, Khotan, and Kashgar in July 2013 were up to $43.9^{\circ} \mathrm{C}, 40.2^{\circ} \mathrm{C}$, and $39.4^{\circ} \mathrm{C}$ respectively. During the whole high-temperature season, in Turpan, the average number of days in which air temperatures were higher than $35^{\circ} \mathrm{C}$ was 98 and the average number of days in which air temperatures were higher than $40^{\circ} \mathrm{C}$ was 34 . Moreover, the daily temperature difference could be up to $17.3^{\circ} \mathrm{C}$. Thus, in this study, this temperature condition is referred to as the climate experiencing significant temperature differences and high temperatures.

2.2. Extreme Dryness. In southern Xinjiang, the annual average precipitation is less than $100 \mathrm{~mm}$; however, the annual evaporation is about $1000-4500 \mathrm{~mm}$. In Turpan, the precipitation in 1998 was $33.4 \mathrm{~mm}$, which was the highest in the recent six decades; in 1976, it was $4.3 \mathrm{~mm}$, which was the lowest [26]. Through the precipitation investigation of major cities along national highways in southern Xinjiang from 1997 to 2006 [27], from Figure 4, it could be found that the precipitation in Kashgar in January was more than that in other cities, but it was still less than $18 \mathrm{~mm}$. The precipitation in Turpan was sparse, and it was less than $4 \mathrm{~mm}$. Hence, it could be deduced that extreme dryness was one of the climatic characteristics in southern Xinjiang. 


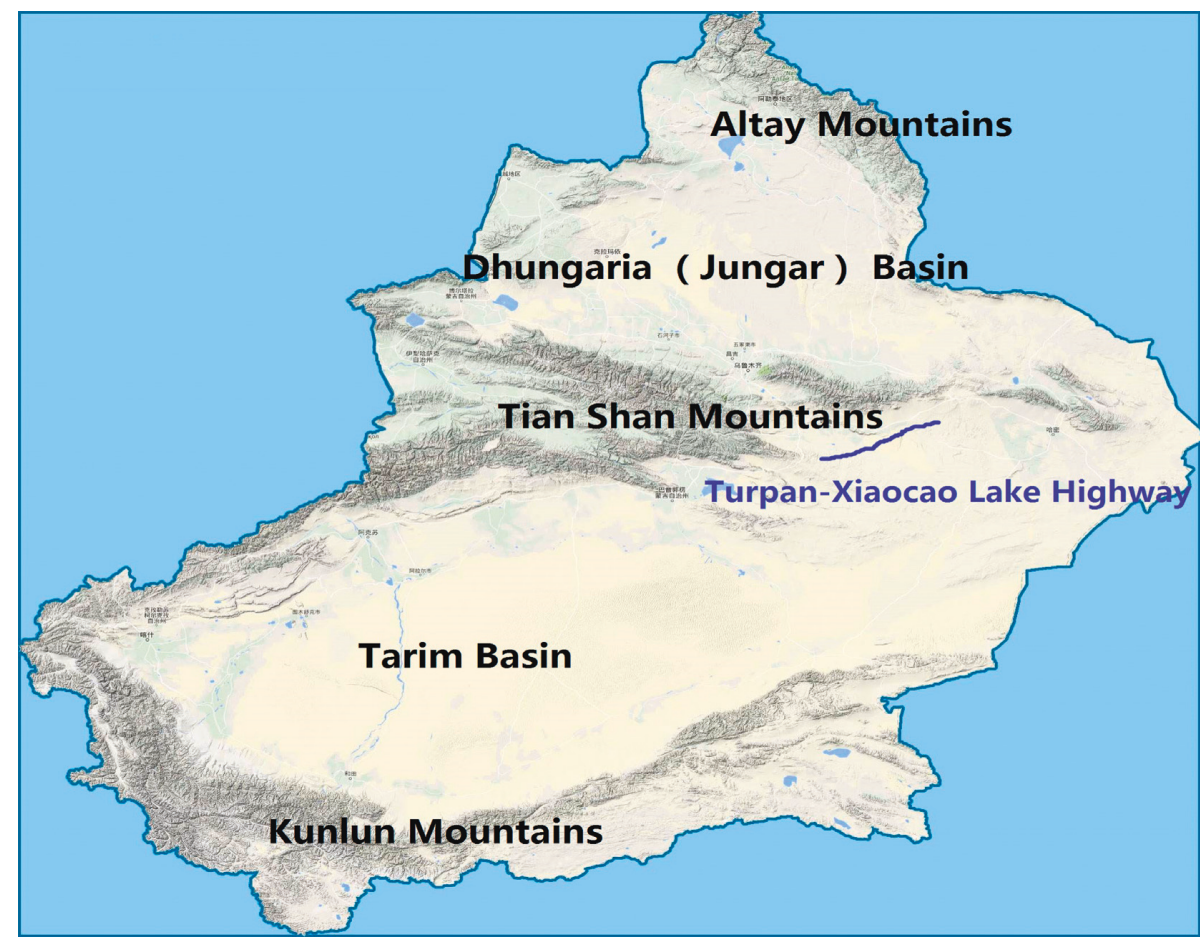

Figure 2: Location of the Turpan-Xiaocao Lake Highway. Source: website of the Xinjiang Bureau of Surveying, Mapping and Geoinformation.

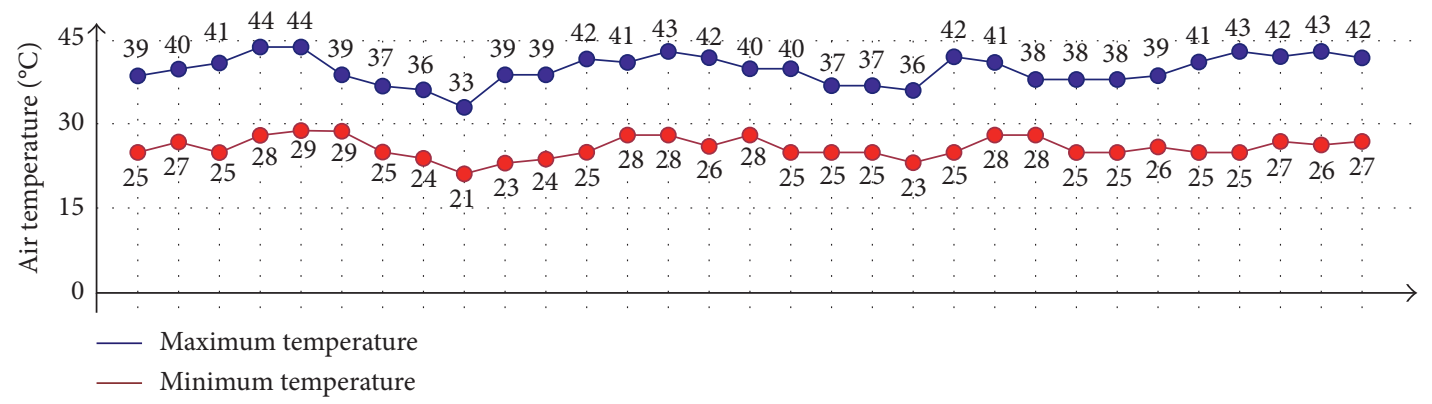

(a)

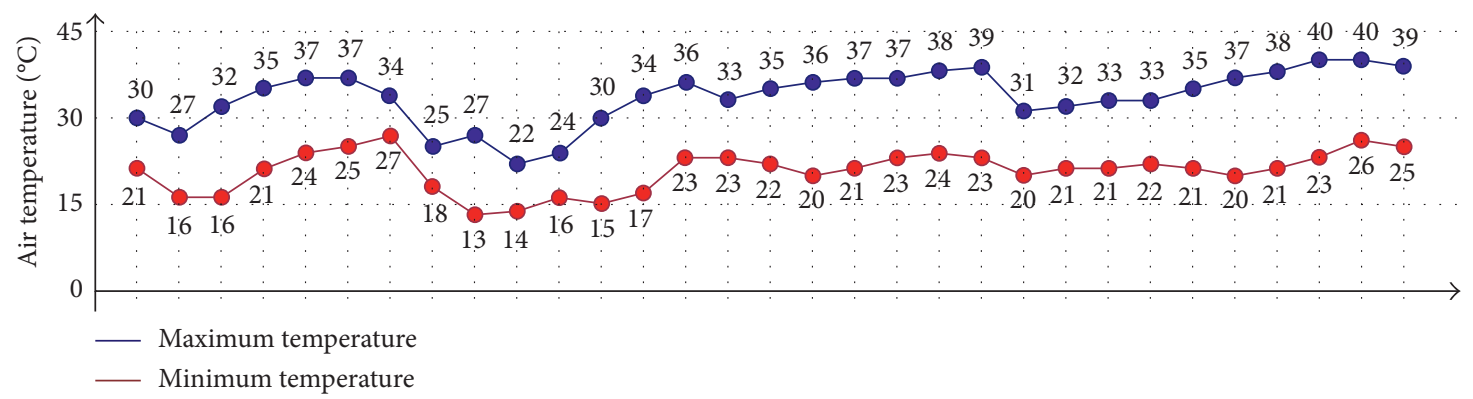

(b)

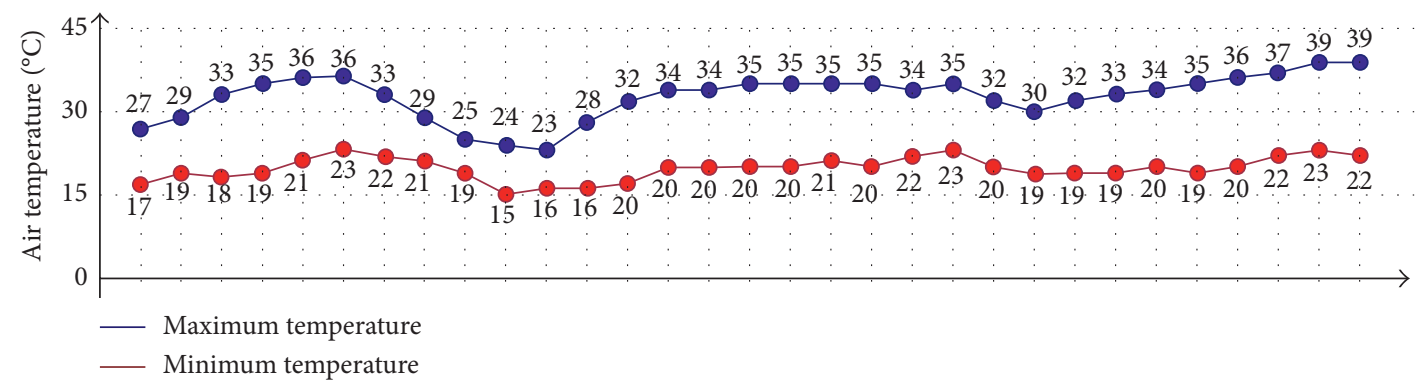

(c)

Figure 3: Daily temperature variation of southern Xinjiang in July 2013: (a) Turpan, (b) Khotan, and (c) Kashgar. 


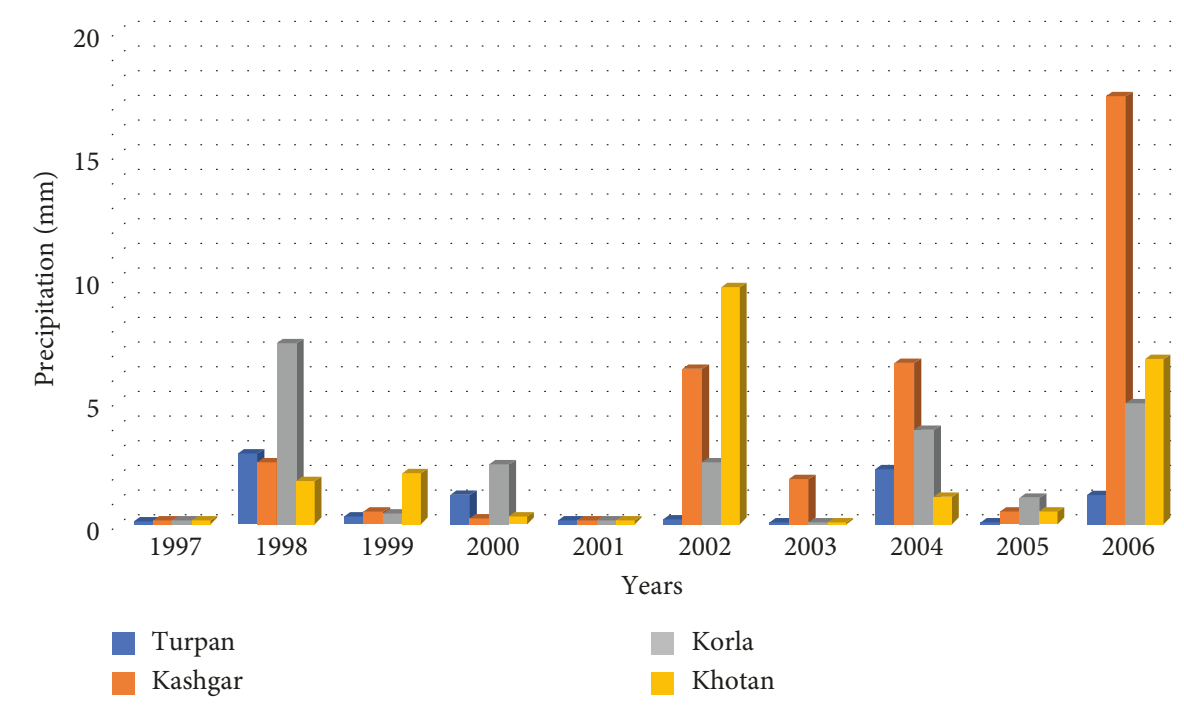

FIgURE 4: The precipitation in southern Xinjiang in January from 1997 to 2006.

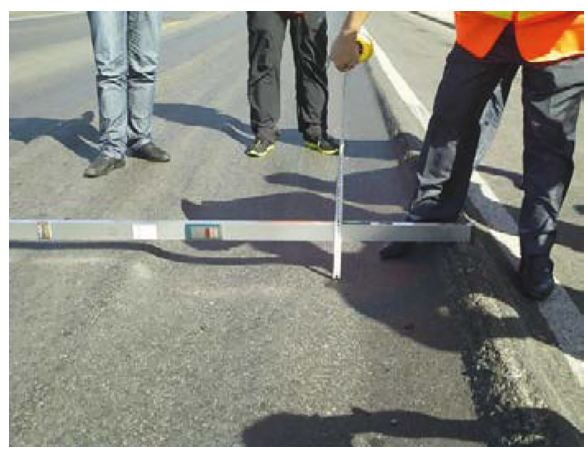

(a)

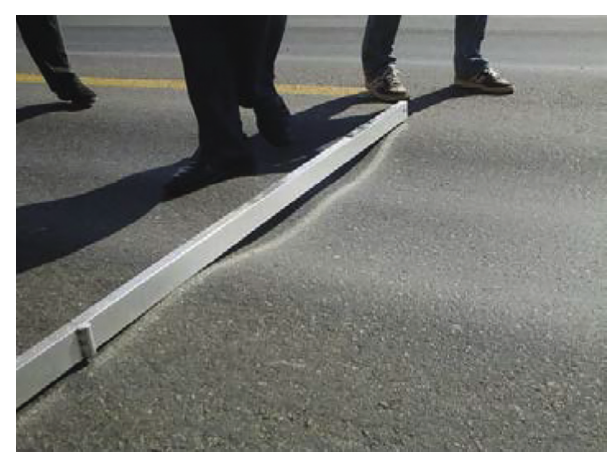

(b)

FIgURE 5: Rutting in southern Xinjiang: (a) no. 314 (Akesu-Kashgar Section); (b) no. 315 (Korla Section).

\section{Investigation of Pavement Distress in Southern Xinjiang}

In this study, pavement distresses of national highway nos. 314 (Hotan Section and Akesu-Kashgar Section), 315 (Korla Section), and 30 (Kumul Section) in southern Xinjiang were investigated. According to the investigation, it was found that asphalt pavement deformation, such as rutting and shoving, is the primary distress in this area.

3.1. Rutting. The investigation results of rutting are shown in Figure 5 and Table 1 . The traffic volumes of national highway nos. 314,315 , and 30 were medium.

Through the investigation of pavement distresses in nos. 314 and 315, it could be found that the average rutting depth of no. 314 (Akesu-Kashgar Section) was $10.5 \mathrm{~mm}$ and the maximum rutting depth was $17 \mathrm{~mm}$, possibly because the thickness of the asphalt course was relatively thin. Moreover, no. 315 (Korla Section) was composed of two asphalt layers. Its average rutting depth was $9.7 \mathrm{~mm}$, and the maximum rutting depth was $12.3 \mathrm{~mm}$. Thus, it could be concluded that the primary reason for serious rutting in southern Xinjiang was the coupling effects of harsh environmental conditions (extremely high temperatures and significant temperature differences) and traffic loads. Besides, shear strength of asphalt mixture would also influence the development of rutting.

3.2. Shoving. Through the investigation, shoving in national highway no. 30 (Kumul Section) is shown in Figure 6, and it was very severe. It was observed that the thickness of the asphalt course of national highway no. 30 (Kumul Section) was very thin and less than $15 \mathrm{~cm}$. Therefore, it could be concluded that relatively thin asphalt courses would easily trigger shoving.

\section{Pavement Structure and FE Model}

4.1. Pavement Structure. According to the local standard of the Xinjiang Highway Asphalt Pavement Design Guide and asphalt pavement structures commonly used in China, seven pavement structures were selected for the Turpan-Xiaocao Lake Highway. They are shown in Table 2. Str-m and Str-1 are often used in southern Xinjiang, and their thickness of asphalt courses are relatively thin compared with other structures. 
TABLE 1: Investigation of rutting in southern Xinjiang in national highway no. 30 (Kumul Section).

\begin{tabular}{|c|c|c|c|c|c|}
\hline PK & $\begin{array}{c}\text { Rutting } \\
\text { length }(\mathrm{m})\end{array}$ & $\begin{array}{c}\text { Rutting } \\
\text { depth }(\mathrm{cm})\end{array}$ & PK & $\begin{array}{c}\text { Rutting } \\
\text { length }(\mathrm{m})\end{array}$ & $\begin{array}{c}\text { Rutting } \\
\text { depth }(\mathrm{cm})\end{array}$ \\
\hline $\mathrm{K} 2923+700-\mathrm{K} 2924+150$ & 450 & 3 & $\mathrm{~K} 2942+300-\mathrm{K} 2943+000$ & 700 & $2.0-4.0$ \\
\hline $\mathrm{K} 2924+150-\mathrm{K} 2924+900$ & 750 & $3.5-5.5$ & $\mathrm{~K} 2944+400-\mathrm{K} 2944+700$ & 300 & 1 \\
\hline $\mathrm{K} 2924+900-\mathrm{K} 2925+350$ & 450 & 11 & $\mathrm{~K} 2945+500-\mathrm{K} 2946+200$ & 700 & $1.0-2.0$ \\
\hline $\mathrm{K} 2925+350-\mathrm{K} 2925+600$ & 250 & $4.0-6.0$ & $\mathrm{~K} 2947+000-\mathrm{K} 2948+000$ & 1000 & 2 \\
\hline $\mathrm{K} 2925+600-\mathrm{K} 2927+300$ & 1700 & $2.0-3.0$ & $\mathrm{~K} 2949+600-\mathrm{K} 2950+400$ & 800 & $1.0-2.0$ \\
\hline $\mathrm{K} 2932+900-\mathrm{K} 2933+500$ & 600 & $2.0-3.0$ & $\mathrm{~K} 2951+400-\mathrm{K} 2951+800$ & 450 & $2.0-3.0$ \\
\hline $\mathrm{K} 2933+500-\mathrm{K} 2933+800$ & 300 & $4.0-5.0$ & $\mathrm{~K} 2951+850-\mathrm{K} 2952+050$ & 200 & 5 \\
\hline $\mathrm{K} 2933+800-\mathrm{K} 2934+000$ & 200 & 7 & $\mathrm{~K} 2952+050-\mathrm{K} 2952+500$ & 450 & $3.0-3.5$ \\
\hline $\mathrm{K} 2934+000-\mathrm{K} 2934+150$ & 150 & $10.0-13.5$ & $\mathrm{~K} 2954+500-\mathrm{K} 2955+800$ & 1300 & 4.5 \\
\hline $\mathrm{K} 2934+150-\mathrm{K} 2934+300$ & 150 & 7 & $\mathrm{~K} 2979+000-\mathrm{K} 2980+200$ & 1200 & 2 \\
\hline $\mathrm{K} 2934+300-\mathrm{K} 2934+500$ & 200 & 6 & $\mathrm{~K} 2991+000-\mathrm{K} 2991+800$ & 800 & 4 \\
\hline $\mathrm{K} 2934+500-\mathrm{K} 2934+950$ & 450 & $2.0-3.0$ & $\mathrm{~K} 2999+000-\mathrm{K} 2999+300$ & 300 & $2.0-3.0$ \\
\hline
\end{tabular}

4.2. Pavement FE Model. In this study, the FE program ANSYS was used. The FE model is shown in Figure 7. The direction of the pavement depth is $y$-direction, and the direction of traffic is $z$-direction. SOLID70 was used for the analysis of temperature fields, and SOLID164 was used for the analysis of mechanical responses. The dimensions of the model are $10 \mathrm{~m} \times 10 \mathrm{~m} \times 10 \mathrm{~m}(x \times z \times y)$.

\section{Boundary Conditions}

5.1. Thermal Boundary Conditions. Radiation, conduction, and convection are the three major ways of heat transfer in a pavement structure, and the solar radiation is the primary influence factor of the pavement temperature field [28].

5.1.1. Radiation. It can be seen that total radiation is mainly composed of solar radiation and pavement radiation in the analysis of pavement temperature fields.

The daily variation of solar radiation in China is given as follows [2]:

$$
q_{\mathrm{rad}}(t)= \begin{cases}0, & \left\{0, \frac{\pi}{\omega}\left(1-\frac{m}{2}\right)\right\}, \\ q_{0} \cos m \omega(t-12), & \left\{\frac{\pi}{\omega}\left(1-\frac{m}{2}\right), \frac{\pi}{\omega}\left(1+\frac{m}{2}\right)\right\}, \\ 0, & \left\{\frac{\pi}{\omega}\left(1+\frac{m}{2}\right), \frac{2 \pi}{\omega}\right\},\end{cases}
$$

where $q_{0}(\mathrm{MJ})$ is the maximum solar radiation at noon, $q_{0}=0.131 m q_{\mathrm{d}}, m=12 / C, C(\mathrm{~h})$ is the time during which sunshine is present in one day, $q_{\mathrm{d}}(\mathrm{MJ})$ is the total solar radiation in one day, and $\omega=2 \pi / 24$.

Pavement radiation follows the Stefan-Boltzmann law and is given by

$$
q_{\mathrm{air}}=\sigma \mathcal{E}\left(T_{\mathrm{air}}^{4}-T_{\mathrm{sur}}^{4}\right),
$$

where $T_{\text {air }}\left({ }^{\circ} \mathrm{C}\right)$ is the air temperature; $T_{\text {sur }}\left({ }^{\circ} \mathrm{C}\right)$ is the pavement surface temperature; $\sigma$ is the Stefan-Boltzmann constant, $\sigma=5.669 \times 10^{-8} \mathrm{~W} /\left(\mathrm{m}^{2} \cdot{ }^{\circ} \mathrm{C}^{4}\right)$; and $\varepsilon$ is the emissivity of the pavement surface; in this study, $\varepsilon=0.7$ [29]. The air

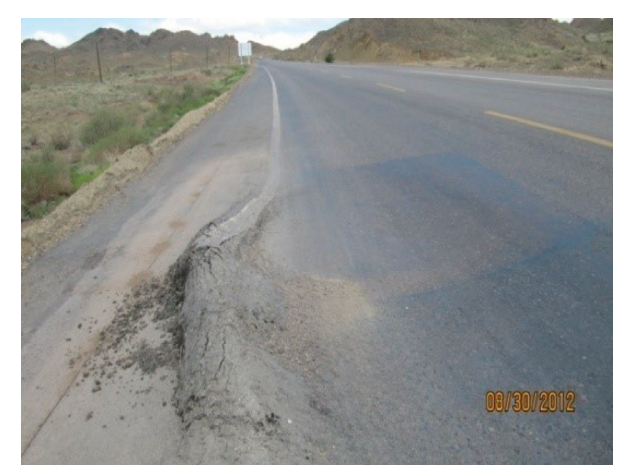

FIgURE 6: Shoving in southern Xinjiang in national highway no. 30 (Kumul Section).

temperature and the pavement surface temperature will be illustrated in detail in Sections 5.1.5 and 5.1.6, respectively.

5.1.2. Convection. The convective heat transfer equation is given as follows:

$$
q_{\mathrm{conv}}=h\left(T_{\mathrm{sur}}-T_{\mathrm{air}}\right)
$$

where $T_{\text {sur }}\left({ }^{\circ} \mathrm{C}\right)$ is the pavement surface temperature, $T_{\text {air }}\left({ }^{\circ} \mathrm{C}\right)$ is the air temperature, and $h\left(\mathrm{~W} /\left(\mathrm{m}^{2} \cdot{ }^{\circ} \mathrm{C}\right)\right)$ is the convective heat-transfer coefficient, which is influenced by wind speed and could be calculated through the following [16]:

$$
h= \begin{cases}4.0 v+5.6, & v<5, \\ 7.1 v^{0.78}, & v>5,\end{cases}
$$

where $v(\mathrm{~m} / \mathrm{s})$ is the wind speed, and in southern Xinjiang, it is $3.8 \mathrm{~m} / \mathrm{s}$ [30].

5.1.3. Conduction. Let the temperature of any point in the pavement structure be $T=T(x, y, z, t)$, where $x, y$, and $z$ are the coordinates of the point and $t$ is the time. The equation of transient heat conduction is given as follows:

$$
\rho c \frac{\partial T}{\partial t}=k\left(\frac{\partial^{2} T}{\partial x^{2}}+\frac{\partial^{2} T}{\partial y^{2}}+\frac{\partial^{2} T}{\partial z^{2}}\right),
$$

where $k\left(\mathrm{~W} /\left({ }^{\circ} \mathrm{C} \cdot \mathrm{m}\right)\right)$ is the thermal conductivity, $\rho\left(\mathrm{kg} / \mathrm{m}^{3}\right)$ is the material density, and $c\left(\mathrm{~J} / \mathrm{kg} /{ }^{\circ} \mathrm{C}\right)$ is the specific heat capacity. 
TABLE 2: Pavement structures selected in this study.

\begin{tabular}{|c|c|c|c|c|c|c|c|}
\hline & STR-m & STR-1 & STR-2 & STR-3 & STR-4 & STR-5 & STR-6 \\
\hline \multirow{6}{*}{$\begin{array}{l}\text { Surface } \\
\text { course }\end{array}$} & $4 \mathrm{~cm}$ & $5 \mathrm{~cm}$ & $4 \mathrm{~cm}$ & $4 \mathrm{~cm}$ & $5 \mathrm{~cm}$ & $4 \mathrm{~cm}$ & $4 \mathrm{~cm}$ \\
\hline & AC-13 & AC-16 & SMA-13 & AC-13 & AC-16 & AC-13 & SMA-13 \\
\hline & $5 \mathrm{~cm}$ & $7 \mathrm{~cm}$ & $6 \mathrm{~cm}$ & $6 \mathrm{~cm}$ & $7 \mathrm{~cm}$ & $6 \mathrm{~cm}$ & $6 \mathrm{~cm}$ \\
\hline & AC-20 & AC-20 & AC-20 & AC-20 & AC-20 & AC-20 & AC-20 \\
\hline & $7 \mathrm{~cm}$ & & $8 \mathrm{~cm}$ & $8 \mathrm{~cm}$ & & $8 \mathrm{~cm}$ & $8 \mathrm{~cm}$ \\
\hline & AC-25 & & AC-25 & AC-25 & & AC-25 & AC-25 \\
\hline \multirow{3}{*}{$\begin{array}{l}\text { Base } \\
\text { course }\end{array}$} & $\begin{array}{c}34 \mathrm{~cm} \text { cement- } \\
\text { treated sand } \\
\text { gravel }\end{array}$ & $\begin{array}{c}35 \mathrm{~cm} \text { cement- } \\
\text { treated sand } \\
\text { gravel }\end{array}$ & $\begin{array}{c}36 \mathrm{~cm} \text { cement- } \\
\text { treated sand } \\
\text { gravel }\end{array}$ & $14 \mathrm{~cm} \mathrm{ATB30}$ & $10 \mathrm{~cm} \mathrm{ATB25}$ & $12 \mathrm{~cm} \mathrm{ATB25}$ & $12 \mathrm{~cm} \mathrm{ATB25}$ \\
\hline & $\begin{array}{l}18 \mathrm{~cm} \text { natural } \\
\text { sand gravel }\end{array}$ & $\begin{array}{c}26 \mathrm{~cm} \text { natural } \\
\text { sand gravel }\end{array}$ & $\begin{array}{l}20 \mathrm{~cm} \text { natural } \\
\text { sand gravel }\end{array}$ & $\begin{array}{l}26 \mathrm{~cm} \text { graded } \\
\text { macadam }\end{array}$ & $\begin{array}{c}36 \mathrm{~cm} \text { cement- } \\
\text { treated sand } \\
\text { gravel }\end{array}$ & $\begin{array}{c}20 \mathrm{~cm} \text { cement- } \\
\text { treated sand } \\
\text { gravel }\end{array}$ & $\begin{array}{c}18 \mathrm{~cm} \text { cement- } \\
\text { treated sand } \\
\text { gravel }\end{array}$ \\
\hline & & & & & $\begin{array}{c}20 \mathrm{~cm} \text { natural } \\
\text { sand gravel }\end{array}$ & $\begin{array}{c}26 \mathrm{~cm} \text { natural } \\
\text { sand gravel }\end{array}$ & $\begin{array}{c}\text { Natural sand } \\
\text { gravel }\end{array}$ \\
\hline $\begin{array}{l}\text { Total } \\
\text { depth }(\mathrm{cm})\end{array}$ & 68 & 73 & 74 & 58 & 78 & 76 & 68 \\
\hline
\end{tabular}

5.1.4. Thermal Boundary at the Bottom of the Pavement Model. It is a common consensus that the environmental influence weakens with the increase in pavement depth, and at a depth of several meters, the temperature change of soil is not obvious, only with the seasonal variation. According to Li [31], in Xinjiang, the temperature variation in the subgrade below a depth of $150 \mathrm{~cm}$ was quite small. Hence, in this study, the subgrade temperature at a depth of $1.5 \mathrm{~m}$ in the subgrade was set as a constant.

Because conditions of significant temperature differences and high temperatures are very special, it is possible that the current prediction model for the subgrade temperature would not be appropriate. To identify the thermal boundary at the bottom of the pavement model, the research of Tang [32] was referred to. In this research, a test road was constructed in Yanqi Hui Autonomous County (referred to as Yanqi), which is also in southern Xinjiang and close to Turpan. The location of Yanqi is shown in Figure 8.

In Tang's research, temperature sensors were set at the depths of $1 \mathrm{~m}$ and $1.5 \mathrm{~m}$ below the subgrade surface, and the subgrade temperature at a depth of $1.5 \mathrm{~m}$ was approximately $20^{\circ} \mathrm{C}$. Hence, the thermal boundary at the bottom of the pavement model in this study was set as $20^{\circ} \mathrm{C}$ in the hightemperature season.

5.1.5. Representative Date Selection. In this study, July 14, 2008, was set as the representative date to ensure the authenticity and representativeness in the analysis of the adaptability of asphalt pavement structures in the Turpan-Xiaocao Lake area in the high-temperature season. As mentioned earlier, Turpan is one of the most scorching counties in the Turpan-Xiaocao Lake area, and the air temperature on July 14, 2008 (maximum temperature: $47.7^{\circ} \mathrm{C}$ ), was one of the highest measured air temperatures in the last decade. The duration of sunshine on July 14,2008, is given in Table 3, and the air temperature is shown in Figure 9.

The hourly solar radiation conditions on the representative date in Turpan were calculated based on (1), Table 3, and the daily solar radiation conditions measured in the research of Liu [33]. It is shown in Figure 10.

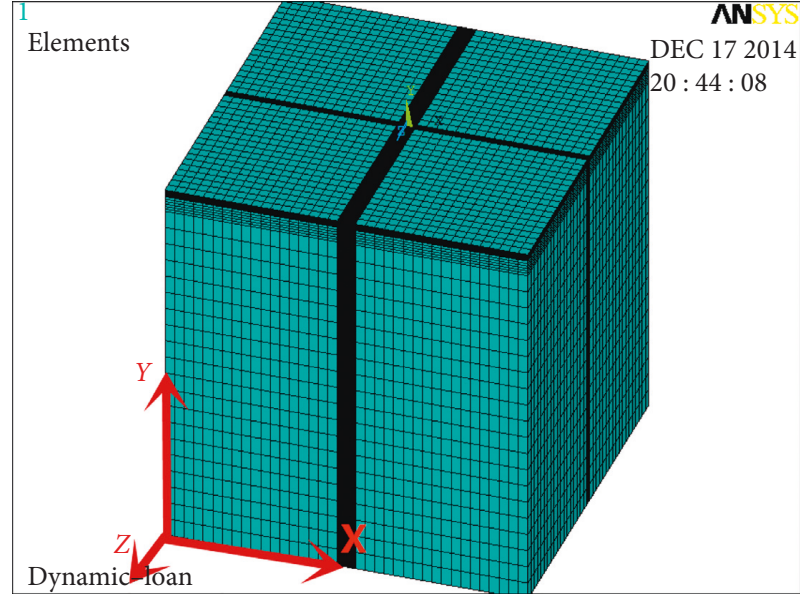

Figure 7: The FE model used in this study.

5.1.6. Pavement Surface Temperature. To calculate pavement radiation and convection, the precondition is to identify the pavement surface temperature, and the research of Tang [32] was referred to because of the following two reasons: First, the condition of significant temperature differences and high temperatures is special, and possibly, the current prediction model for pavement surface temperatures would not be applicable. Second, the case study engineering of the TurpanXiaocao Lake Highway was not completed because it was difficult to measure its pavement surface temperature directly.

In the research of Tang, the pavement surface temperature in Yanqi could be estimated using the following equation:

$$
T_{\text {sur }}=1.0852 T_{\text {air }}-0.0684 h+4.29,
$$

where $T_{\text {sur }}\left({ }^{\circ} \mathrm{C}\right)$ is the pavement surface temperature, $T_{\text {air }}\left({ }^{\circ} \mathrm{C}\right)$ is the air temperature, and $h(\mathrm{~m})$ is the pavement depth.

5.2. Mechanical Boundary Condition and Traffic Loads. In this paper, Dongfeng EQ-140 was selected as the representative vehicle and its technical parameters are shown in 


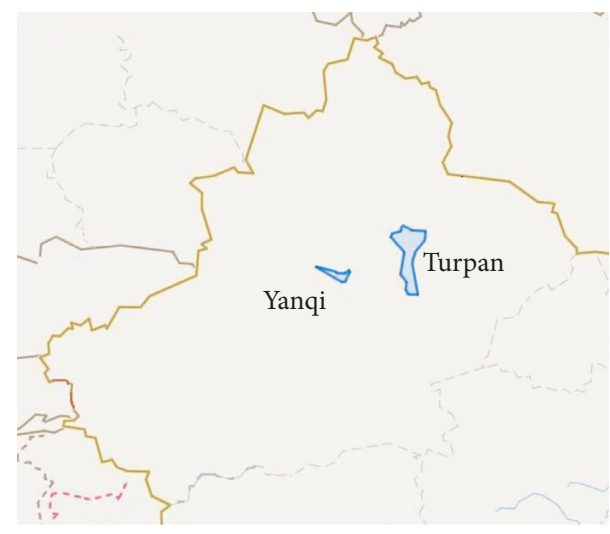

FIgURE 8: Location of Yanqi and Turpan.

TABle 3: Duration of sunshine on the representative date.

\begin{tabular}{lcccc}
\hline Location & Date & $\begin{array}{c}\text { Sunrise } \\
\text { time }\end{array}$ & $\begin{array}{c}\text { Sunset } \\
\text { time }\end{array}$ & $\begin{array}{c}\text { Sunshine } \\
\text { duration }\end{array}$ \\
\hline Turpan & $14 / 7 / 2008$ & $06: 45$ & $21: 39$ & $14: 54$ \\
\hline
\end{tabular}

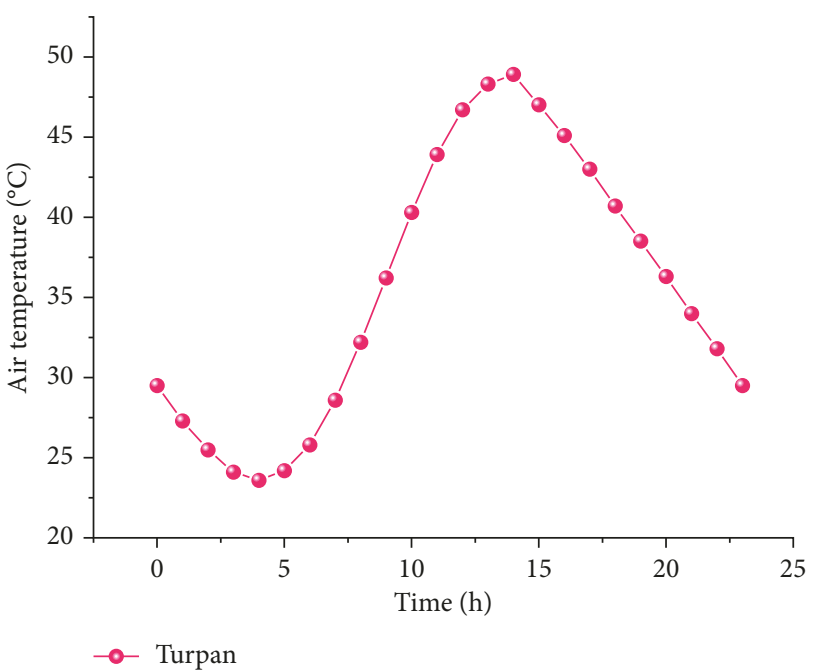

Figure 9: Air temperature on the representative date in Turpan.

Li's research [34]. The tire load was simplified as the uniformly distributed rectangular load since it was the whole pavement response under the coupling effects of significant temperature differences, high temperatures, and traffic loads that were studied in this paper.

In the process of driving, due to the unevenness of the pavement surface and the vibration of vehicles, effects of vehicles on the pavement could be divided into four categories, as shown in Figure 11.

In this paper, to simplify the calculation and simulation, traffic loads could be estimated using the haversine function as follows [35]:

$$
\begin{aligned}
& P(t)=P_{\max } \sin \left(\pi \frac{t}{T}\right), \\
& P_{\max }=P \cdot \mathrm{DAF},
\end{aligned}
$$

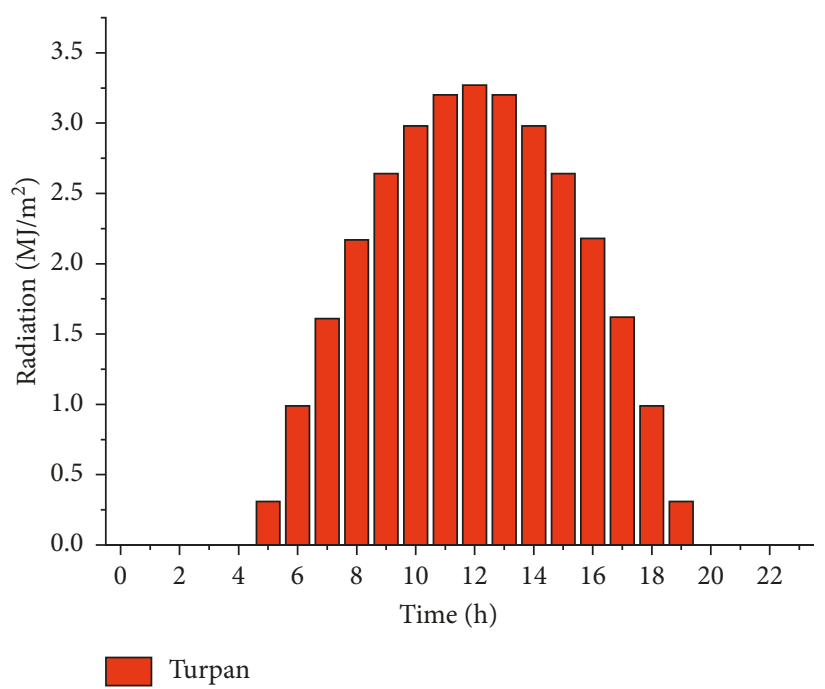

FIgURE 10: Radiation conditions on representative dates.

where $P_{\max }(\mathrm{MPa})$ is the peak value of the vibrating load; $T$ (s) is the period of traffic loads; $t(\mathrm{~s})$ is the time; $P(\mathrm{MPa})$ is the uniformly distributed traffic loads, $P=0.7 \mathrm{MPa}$ in China; and DAF is the dynamic amplification factor. It is given by

$$
\mathrm{DAF}=1+a \sqrt{V},
$$

where $V(\mathrm{~km} / \mathrm{h})$ is the speed; in this study, $V=80 \mathrm{~km} / \mathrm{h}$ based on the investigation of vehicle speed in southern Xinjiang [36]. $a$ is the riding quality evaluation factor, correlated with IRI, and in this study, $a=0.035$ [37].

$T$ could be calculated using the following equation:

$$
T=\frac{12 R}{v},
$$

where $R(\mathrm{~m})$ is the equivalent radius of the single-wheel load, $R=3 L / 2$, in which $L$ is the length of the uniformly distributed rectangular load; in this study, $L=19.2 \mathrm{~cm}$, and $v(\mathrm{~m} / \mathrm{s})$ is the speed.

\section{Asphalt Pavement Materials Parameters}

6.1. Viscoelasticity of Asphalt Mixture. Asphalt mixture exhibits strong viscoelasticity under ambient temperature, and in this paper, the generalized Kelvin model is employed and shown in Figure 12. Its creep compliance could be expressed as Prony series [38]:

$$
\begin{aligned}
D(t) & =D_{0}+\frac{1}{\eta_{0}} t+\sum_{i=1}^{n} D_{i}\left(1-e^{-\left(t / \tau_{i}\right)}\right), \\
D_{i} & =\frac{1}{E_{i}}, \\
\tau_{i} & =\frac{\eta_{i}}{E_{i}},
\end{aligned}
$$

where $E_{i}, \eta_{i}$, and $\tau_{i}$ are the spring stiffness, dashpot viscosity, and retardation time of the Kelvin element $i$. Besides, $D_{0}, D_{i}$, and $\eta_{0}$ are Prony series parameters. 


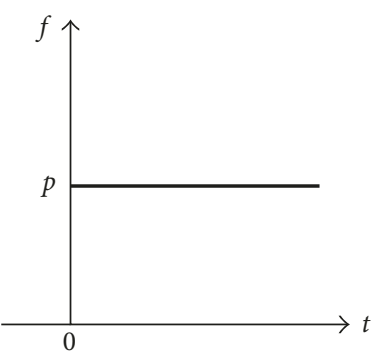

(a)

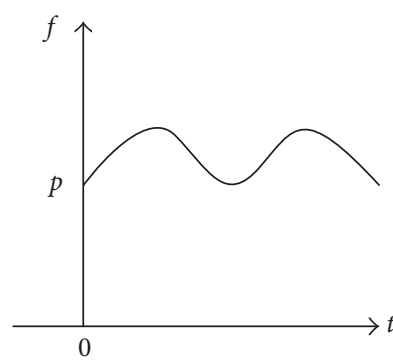

(b)

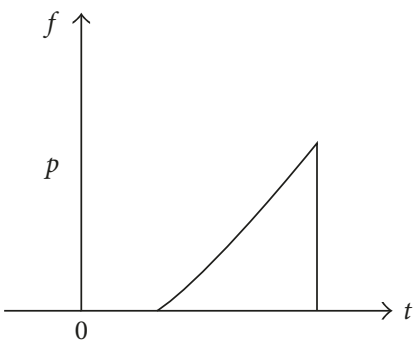

(c)

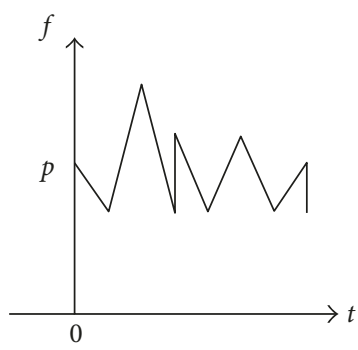

(d)

FIgURE 11: Four typical categories of traffic loads: (a) constant load, (b) harmonic load, (c) impact load, and (d) random load.

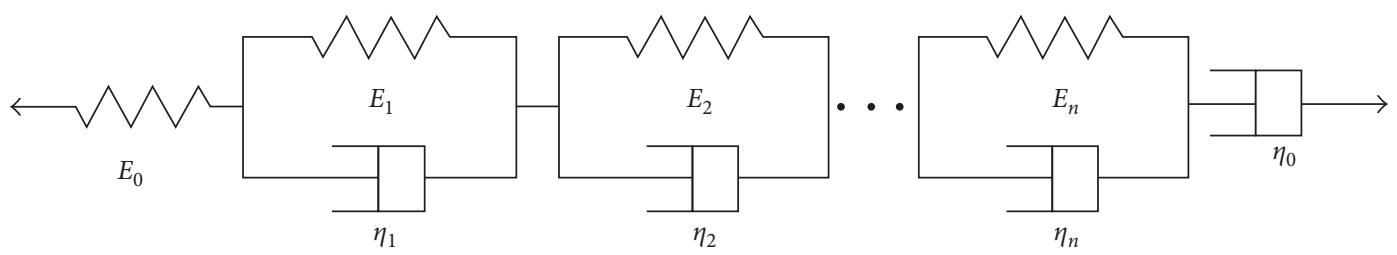

FIGURE 12: The generalized Kelvin model.

In practice, it has been found that the generalized Kelvin model should consist of six Kelvin elements to properly characterize the behavior of asphalt materials [39], which means that the Prony series function contains 14 unknown parameters $\left(D_{0}, \eta_{0}, D_{i}\right.$, and $\left.\tau_{i}\right)$ in (11).

In this case, to simplify the calculation, a model from Ho and Romero's research [39] was utilized to invert the Laplace transform of the Prony series function and to predict the relaxation moduli of asphalt mixtures with the Burgers model, as shown in Figure 13.

Through the Laplace transform, the following equation could be obtained from (11):

$$
\widehat{D}(s)=\frac{D_{0}}{s}+\frac{1}{\eta_{0} \cdot s^{2}}+\sum_{i=1}^{n} D_{i}\left(1-\frac{1 / \tau_{i}}{s\left(s+1 / \tau_{i}\right)}\right)
$$

Moreover, the interconversion relation between creep compliance and relaxation modulus in the Laplace domain is shown as follows:

$$
\widehat{D}(s) \widehat{E}(s)=\frac{1}{s^{2}} .
$$

Therefore, (12) could be rewritten as follows:

$$
\widehat{E}(s)=\frac{\eta_{0} \prod_{i=1}^{n}\left(s+1 / \tau_{i}\right)}{D_{0} \cdot \eta_{0} \cdot s \cdot \prod_{i=1}^{n}\left(s+1 / \tau_{i}\right)+\sum_{i=1}^{n} D_{i} \cdot 1 / \tau_{i} \cdot \eta_{0} \cdot s+\prod_{i=1}^{n}\left(s+1 / \tau_{i}\right)} .
$$

When the Burgers model is used, (14) could be rearranged as follows:

$$
\widehat{E}(s)=\frac{\eta_{0} \cdot s+\left(\eta_{0} / \tau_{1}\right)}{A s^{2}+B s+C},
$$

where $A=D_{0} \cdot \eta_{0}, B=D_{0} \cdot\left(\eta_{0} / \tau_{1}\right)+D_{1} \cdot\left(\eta_{0} / \tau_{1}\right)+1$, and $C=1 / \tau_{1}$.

According to the factorization principle, (15) can be rearranged as follows:

$$
\begin{aligned}
\widehat{E}(s) & =\frac{\eta_{0} \cdot(s+(B / 2 A))+\eta_{0} \cdot\left(\left(1 / \tau_{i}\right)-(B / 2 A)\right)}{A \cdot\left[(s+(B / 2 A))^{2}+\left((C / A)-\left(B^{2} / 4 A^{2}\right)\right)\right]} \\
& =\frac{\eta_{0}}{A} \cdot \frac{s+(B / 2 A)}{(s+(B / 2 A))^{2}-\left(\left(B^{2} / 4 A^{2}\right)-(C / A)\right)}+\frac{\left(\eta_{0} / \tau_{1}\right)-\left(\eta_{0} \cdot B / 2 A\right)}{A \cdot \sqrt{\left(B^{2} / 4 A^{2}\right)-(C / A)}} \cdot \frac{\sqrt{\left(B^{2} / 4 A^{2}\right)-C / A}}{(s+(B / 2 A))^{2}-\left(\left(B^{2} / 4 A^{2}\right)-(C / A)\right)} \\
& =\frac{\eta_{0}}{A} \cdot \frac{s+\beta}{(s+\beta)^{2}-\alpha^{2}}+\frac{\left(\eta_{0} / \tau_{1}\right)-\eta_{0} \cdot \beta}{A \cdot \alpha} \cdot \frac{\alpha}{(s+\beta)^{2}-\alpha^{2}},
\end{aligned}
$$


where $\beta=B / 2 A$ and $\alpha=\sqrt{\left(B^{2} / 4 A^{2}\right)-(C / A)}$

Considering the first shifting theorem of the Laplace transform,

$$
L\left\{e^{-\beta \cdot t} E(t)\right\}=\widehat{E}(s+\beta),
$$

where $s$ is a Laplace transform parameter, $\beta$ is a constant, and $s-\beta>0$.

Hence, the right-hand side of (16) could be solved directly, and the first term on the right-hand side of (16) becomes

$$
E_{s+\beta}=\frac{\eta_{0}}{A} \cdot e^{-\beta \cdot t} \cdot \cosh (\alpha \cdot t) \cdot u(t),
$$

where $u(t)$ is determined as an unit step function shown as follows:

$$
u(t)= \begin{cases}1, & \text { if } t>0 \\ 0, & \text { if } t \leq 0\end{cases}
$$

The second term on the right-hand side of (16) is calculated as follows:

$$
E_{s}=\frac{\eta_{0} \cdot\left(\left(1 / \tau_{1}\right)-\beta\right)}{A \cdot \alpha} \cdot e^{-\beta \cdot t} \cdot \sinh (\alpha \cdot t) \cdot u(t) .
$$

Besides, hyperbolic sine and cosine functions can be replaced with an exponential function:

$$
\begin{aligned}
& \sinh t=\frac{1}{2}\left(e^{t}-e^{-t}\right), \\
& \cosh t=\frac{1}{2}\left(e^{t}+e^{-t}\right) .
\end{aligned}
$$

Therefore, the inverse Laplace transform of (16) becomes

$$
E(t)=C_{1} \cdot\left[e^{(\alpha-\beta) \cdot t}+e^{-(\alpha+\beta) \cdot t}\right]+C_{2} \cdot\left[e^{(\alpha-\beta) \cdot t}-e^{-(\alpha+\beta) \cdot t}\right]
$$

where $C_{1}=\eta_{0} / 2 A$ and $C_{2}=\left(\left(\eta_{0} / \tau_{1}\right)-\left(\eta_{0} \cdot \beta\right)\right) / 2 A \cdot \alpha$.

According to [40-42] and anonymous authors, values of $E_{0}, E_{1}, \eta_{0}$, and $\eta_{1}$ are shown in Table 4 .

6.2. Thermophysical and Mechanical Parameters. The thermophysical and mechanical parameters are listed in Tables 5 and 6 [43], respectively, based on Chinese Specifications for Design of Highway Asphalt Pavement (JTG D50-2017). The dynamic modulus of asphalt mixture in Table 6 is that under $20^{\circ} \mathrm{C}$ and $10 \mathrm{~Hz}$. Although humidity can affect the thermophysical and mechanical parameters, its influence was not considered, given the extreme dryness in southern Xinjiang.

\section{Results and Analysis}

To analyze the adaptability of seven pavement structures, thermal loads and traffic loads were both applied. First, the original structure temperature was determined through steady-state analysis. Then, transient temperature loads and traffic loads were applied at hourly intervals. Because of the serious deformation distress in southern Xinjiang, the temperature field in the temperature-increasing phase was extensively simulated, and mechanical responses related to deformation were analyzed in this study.

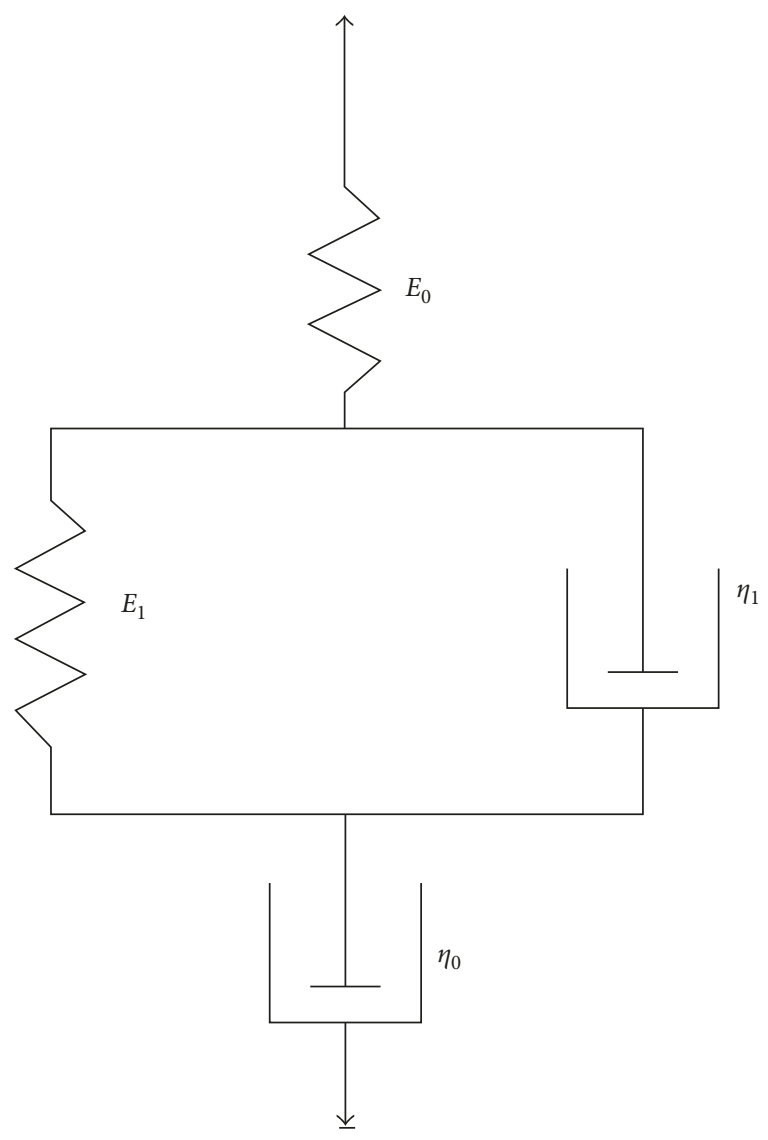

FIgURE 13: The Burgers model.

7.1. Analysis of Pavement Temperature Fields in the TurpanXiaocao Lake Area. The simulation results of pavement temperature fields in the Turpan-Xiaocao Lake area on the representative date, that is, July 14, 2008, are shown in Figures 14(a)-14(d).

From Figures 14(a)-14(d), it was found that the variation of structure temperatures exhibited a time lag compared with that of air temperatures, which increased with pavement depth. For example, in Str-m, the time lag at the bottom of the upper asphalt course was $2 \mathrm{~h}$; however, it was $5 \mathrm{~h}$ at the bottom of the lower asphalt course and $7 \mathrm{~h}$ at the bottom of the upper base course. Moreover, it was found that temperature variation became increasingly indistinct with the increase of pavement depth. For example, in Str-m, the temperature variation at the bottom of the upper asphalt course was more than $10^{\circ} \mathrm{C}$; however, it was less than $3^{\circ} \mathrm{C}$ at the bottom of the upper base course.

Furthermore, the influence of air temperature on each structure was different, and it had the greatest impact on Str-1 among seven structures. Possibly, it was due to the thinnest asphalt course of Str-1. The ranges of temperature variation at the bottom of the lower asphalt course decreased in the following order: Str- $1>$ Str- $2>$ Str- $3>$ Str-m $>$ Str- $6>$ Str- $4>$ Str-5.

In addition, it was found that temperatures of Str-3, Str-5, and Str- 6 at the bottom of the upper base course were higher than those of other structures. It was probable that these three structures consisted of four asphalt mixture layers, and the thermal conductivities of asphalt mixtures were better than 
TABLe 4: Parameters of the Burgers model.

\begin{tabular}{|c|c|c|c|c|c|c|c|}
\hline & & AC-13 & AC- 16 & AC-20 & AC-25 & ATB-25 & ATB-30 \\
\hline \multirow{4}{*}{$20^{\circ} \mathrm{C}$} & $E_{0}(\mathrm{~Pa})$ & $9.92 E+08$ & $8.68 E+08$ & $7.56 E+08$ & $7.15 E+08$ & $3.12 E+08$ & $2.35+08$ \\
\hline & $E_{1}(\mathrm{~Pa})$ & $5.64 E+08$ & $1.53 E+08$ & $2.04 E+08$ & $1.96 E+08$ & $5.42 E+07$ & $4.89+07$ \\
\hline & $\eta_{0}(\mathrm{~Pa} \cdot \mathrm{s})$ & 2016431 & 3817940 & 4227813 & 4134785 & 2601785 & 2403658 \\
\hline & $\eta_{1}(\mathrm{~Pa} \cdot \mathrm{s})$ & 136472 & 334712 & 433027 & 416589 & 284716 & 271648 \\
\hline \multirow{4}{*}{$50^{\circ} \mathrm{C}$} & $E_{0}(\mathrm{~Pa})$ & $3.78 E+08$ & $9.80 E+07$ & $7.37 E+07$ & $7.12 E+07$ & $3.68 E+07$ & $3.23+07$ \\
\hline & $E_{1}(\mathrm{~Pa})$ & $6.83 E+07$ & $3.05 E+07$ & $3.42 E+07$ & $3.02 E+07$ & $1.05 E+07$ & $9.68+06$ \\
\hline & $\eta_{0}(\mathrm{~Pa} \cdot \mathrm{s})$ & 476312 & 681247 & 731707 & 714025 & 384625 & 347851 \\
\hline & $\eta_{1}(\mathrm{~Pa} \cdot \mathrm{s})$ & 36712 & 54138 & 61424 & 58963 & 32478 & 30126 \\
\hline \multirow{4}{*}{$60^{\circ} \mathrm{C}$} & $E_{0}(\mathrm{~Pa})$ & $3.05 E+08$ & $6.35 E+07$ & $5.36 E+07$ & $4.85 E+07$ & $2.34 E+07$ & $1.35 E+07$ \\
\hline & $E_{1}(\mathrm{~Pa})$ & $5.52 E+07$ & $2.86 E+07$ & $3.04 E+07$ & $2.89 E+07$ & $8.76 E+06$ & $8.01 E+06$ \\
\hline & $\eta_{0}(\mathrm{~Pa} \cdot \mathrm{s})$ & 164235 & 471236 & 566247 & 531786 & 193264 & 261789 \\
\hline & $\eta_{1}(\mathrm{~Pa} \cdot \mathrm{s})$ & 58764 & 86172 & 89974 & 87423 & 53762 & 56134 \\
\hline \multirow{4}{*}{$70^{\circ} \mathrm{C}$} & $E_{0}(\mathrm{~Pa})$ & $2.03 E+08$ & $3.90 E+07$ & $2.29 E+07$ & $2.03 E+07$ & $9.45 E+06$ & $9.26 E+06$ \\
\hline & $E_{1}(\mathrm{~Pa})$ & $4.28 E+07$ & $2.05 E+07$ & $2.77 E+07$ & $2.56 E+07$ & $6.72 E+06$ & $6.17 E+06$ \\
\hline & $\eta_{0}(\mathrm{~Pa} \cdot \mathrm{s})$ & 98452 & 105846 & 117804 & 102105 & 98421 & 95463 \\
\hline & $\eta_{1}(\mathrm{~Pa} \cdot \mathrm{s})$ & 76128 & 123634 & 146463 & 128936 & 74126 & 70756 \\
\hline
\end{tabular}

TABLE 5: Thermophysical and mechanical parameters of asphalt mixtures.

\begin{tabular}{|c|c|c|c|c|c|c|}
\hline Material & $\begin{array}{c}\text { Density } \\
\rho\left(\mathrm{kg} / \mathrm{m}^{3}\right) \\
\end{array}$ & $\begin{array}{l}\text { Specific heat } \\
\left(\mathrm{J} /\left(\mathrm{kg} \cdot{ }^{\circ} \mathrm{C}\right)\right)\end{array}$ & $\begin{array}{l}\text { Thermal conductivity } \\
\left(\mathrm{W} /\left(\mathrm{m} \cdot{ }^{\circ} \mathrm{C}\right)\right)\end{array}$ & $\begin{array}{l}\text { Coefficient of thermal } \\
\text { expansion }\left(\mathrm{m}^{-3} / \mathrm{m}\right)\end{array}$ & $\begin{array}{c}\text { Dynamic modulus } \\
E^{*}(\mathrm{MPa}) \\
\end{array}$ & $\begin{array}{c}\text { Poisson's } \\
\text { ratio } \mu \\
\end{array}$ \\
\hline AC-13 & 2400 & 1168 & $0.8-1.0$ & $2 e-5$ & $8000 \sim 12000$ & 0.25 \\
\hline AC-16 & 2450 & 975 & $0.9-1.2$ & $2 e-5$ & $9000 \sim 13500$ & 0.25 \\
\hline AC-20 & 2480 & 785 & $0.9-1.2$ & $2 e-5$ & $9000 \sim 13500$ & 0.25 \\
\hline AC-25 & 2505 & 815 & $1.2-1.4$ & $2 e-5$ & $9000 \sim 13500$ & 0.25 \\
\hline ATB-25 & 2500 & 815 & $1.2-1.4$ & $2 e-5$ & $7000 \sim 11000$ & 0.35 \\
\hline ATB-30 & 2505 & 520 & $1.2-1.4$ & $2 e-5$ & $7000 \sim 11000$ & 0.35 \\
\hline
\end{tabular}

TABLE 6: Thermophysical and mechanical parameters of chemical-treated and other pavement materials.

\begin{tabular}{|c|c|c|c|c|c|c|}
\hline Material & $\begin{array}{c}\text { Density } \rho \\
\left(\mathrm{kg} / \mathrm{m}^{3}\right)\end{array}$ & $\begin{array}{l}\text { Specific heat } \\
\left(\mathrm{J} /\left(\mathrm{kg} \cdot{ }^{\circ} \mathrm{C}\right)\right)\end{array}$ & $\begin{array}{c}\text { Thermal conductivity } \\
\left(\mathrm{W} /\left(\mathrm{m} \cdot{ }^{\circ} \mathrm{C}\right)\right)\end{array}$ & $\begin{array}{l}\text { Coefficient of thermal } \\
\text { expansion }\left(\mathrm{m}^{-3} / \mathrm{m}\right)\end{array}$ & $\begin{array}{c}\text { Dynamic modulus } \\
E^{*}(\mathrm{MPa}) \\
\end{array}$ & $\begin{array}{c}\text { Poisson's } \\
\text { ratio } \mu\end{array}$ \\
\hline Cement-treated sand gravel & 2300 & 825 & $1.1-1.3$ & $1 e-5$ & $14000 \sim 20000$ & 0.25 \\
\hline Natural sand gravel & 1600 & 875 & $1.3-1.6$ & $1.5 e-5$ & 350 & 0.35 \\
\hline Graded macadam & 2250 & 820 & $1.2-1.4$ & $1 e-5$ & 150 & 0.35 \\
\hline Subgrade & 1700 & 860 & $1.2-1.4$ & $50 e-5$ & 65 & 0.4 \\
\hline
\end{tabular}

those of chemical-treated materials. Hence, they had the advantage in transferring the temperature downward. However, there were no distinct differences in pavement temperatures among seven structures when the depth was $60 \mathrm{~cm}$, which means that the selection of the pavement structure form has little influence on the temperature of the subgrade.

7.2. Analysis of Pavement Temperature Adaptability in the Turpan-Xiaocao Lake Area. Due to the serious deformation distress in southern Xinjiang in the high-temperature season, in this paper, rutting, deflection, and compressive strains at the subgrade top surface were used to evaluate the adaptability of pavement structures to significant temperature differences and high temperatures.

According to the simulation results of temperature fields in Section 7.1, coupling effects of traffic loads and temperature at 16:00 were applied on Str-m, Str-1, and Str-2; effects of traffic loads and temperature at 14:00 were applied on Str-3; and effects of traffic loads and temperature at 15:00 were applied on Str-4, Str-5, and Str-6 because for each structure at that time, temperatures at the bottom of the upper asphalt courses were the highest.

7.2.1. Rutting and Shear Stress of the Asphalt Course. The cumulation of traffic loads is one of the most important reasons for the rapid development of rutting in areas experiencing high temperatures and significant temperature differences. Thus, first in this paper, cumulative standard axle loads $(0.7 \mathrm{MPa})$ of a million times were applied on seven pavement structures. The simulation results of rutting are shown in Figure 15.

Besides, there is a viewpoint worldwide that one of the most important reasons for rutting was the insufficient shear resistance. Hence, the maximum shear stresses of asphalt courses under the coupling effects of high temperatures and traffic loads are extracted and shown in Figure 16. 


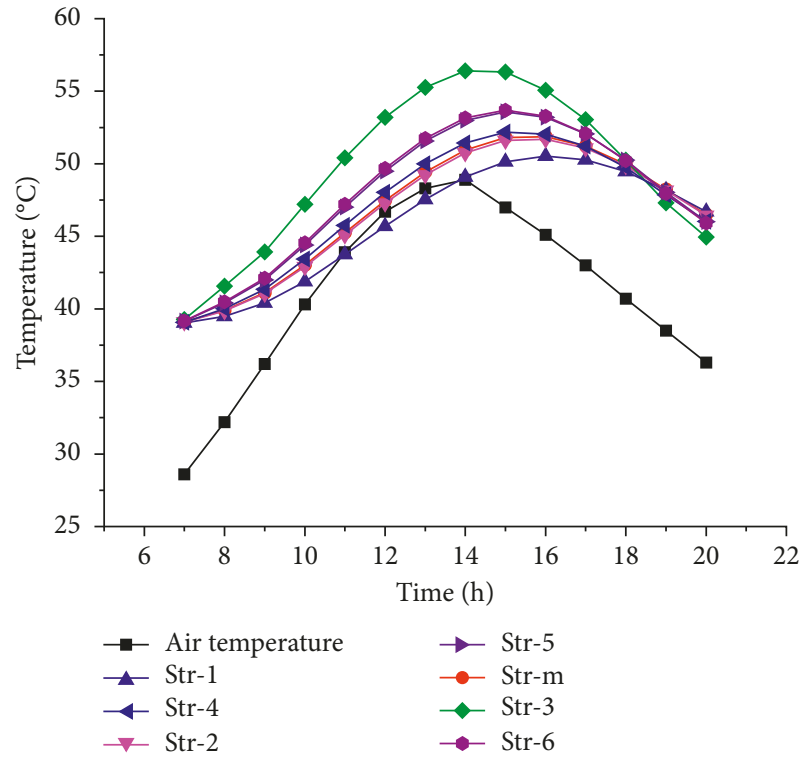

(a)

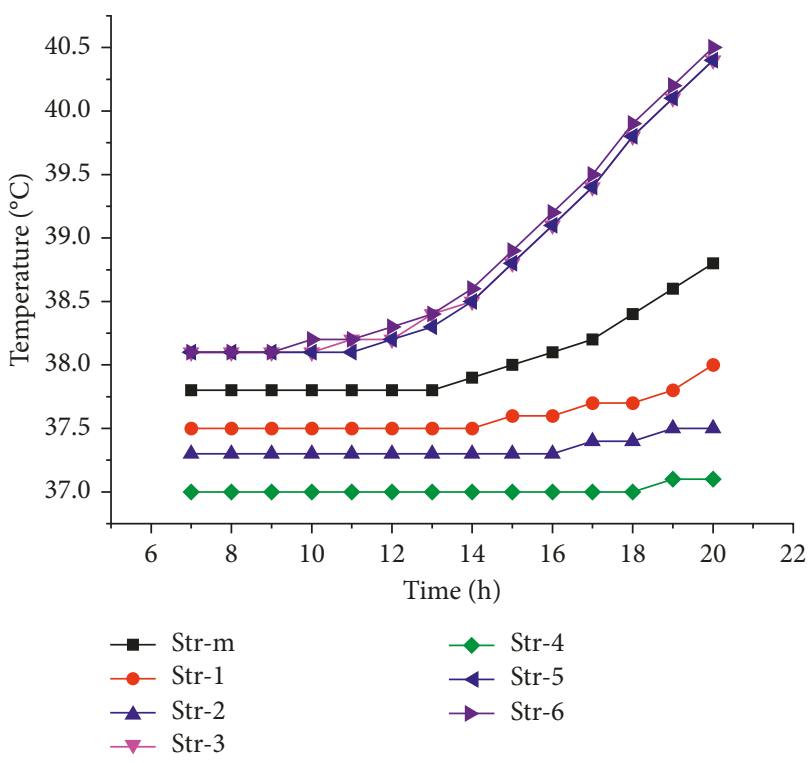

(c)

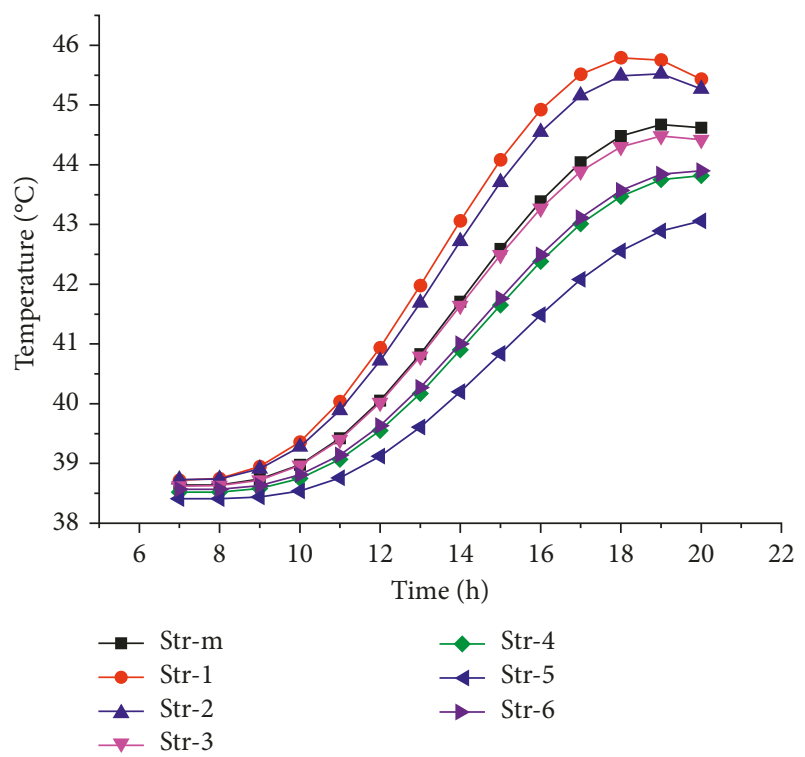

(b)

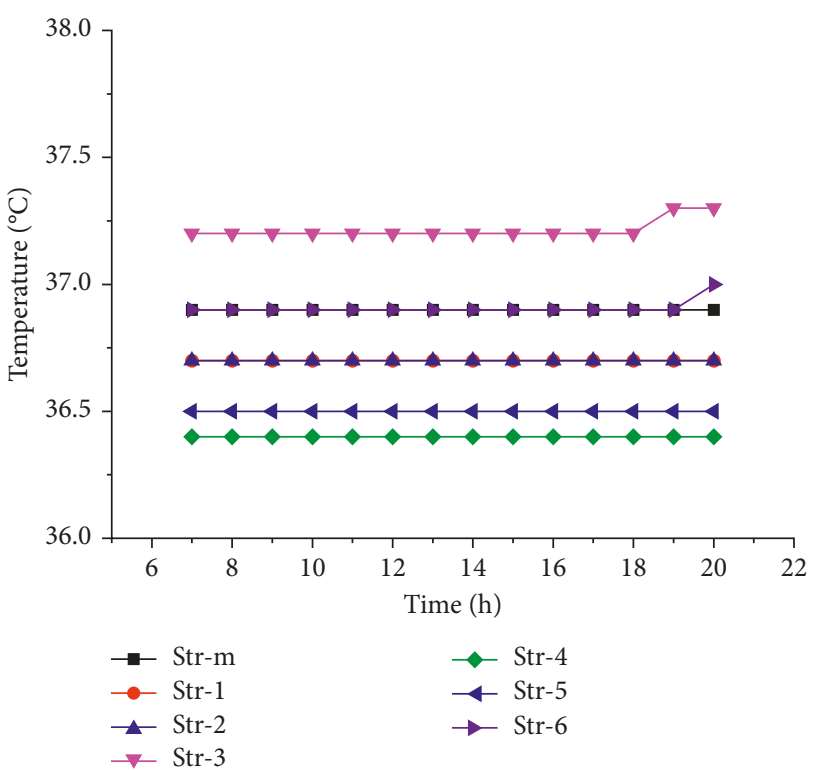

(d)

FIGURE 14: Structure temperature at different depths: (a) temperature variation at the bottom of upper asphalt surface courses, (b) temperature variation at the bottom of lower asphalt surface courses, (c) temperature variation at the bottom of upper base courses, and (d) temperature variation at the bottom of lower base courses.

Seven pavement structures could be divided into three categories: pavements using only chemical-treated bases, that is, Str-m, Str-1, and Str-2; the pavement using a flexible base, that is, Str-3; and pavements using compound bases of both chemicaltreated bases and flexible bases, that is, Str-4, Str-5, and Str-6.

From Figure 15, it could be found that rutting depths of structures using compound bases were the smallest and those of structures using chemical-treated bases were the highest, which was consistent with results of the maximum shear stresses from Figure 16.

From Figure 15, it was also observed that, in pavements using only chemical-treated bases, the rutting depth increased with the increase of the thickness of asphalt courses. The rutting depths of Str-1, Str-m, and Str-2 were $5.073 \mathrm{~mm}$, $4.722 \mathrm{~mm}$, and $3.765 \mathrm{~mm}$ respectively. Hence, it could be deduced that when a proper base and subbase were used, with the increase of the thickness of asphalt courses, the development of rutting depths could be controlled effectively.

In pavements using the compound base, the rutting depth of Str- 4 was the lowest $(3.315 \mathrm{~mm})$, but the maximum shear stress of Str- 4 was the largest $(0.261 \mathrm{MPa})$. Possibly, it was correlated with the form of the pavement structure. First, its chemical-treated base was relative thicker compared with Str-5 and Str-6, possibly resulting in the smaller rutting 


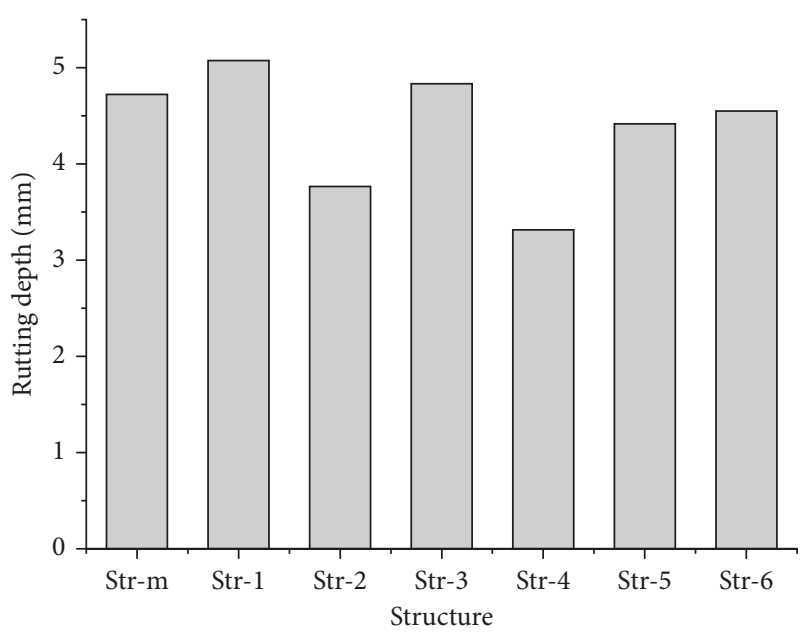

Figure 15: Rutting depth.

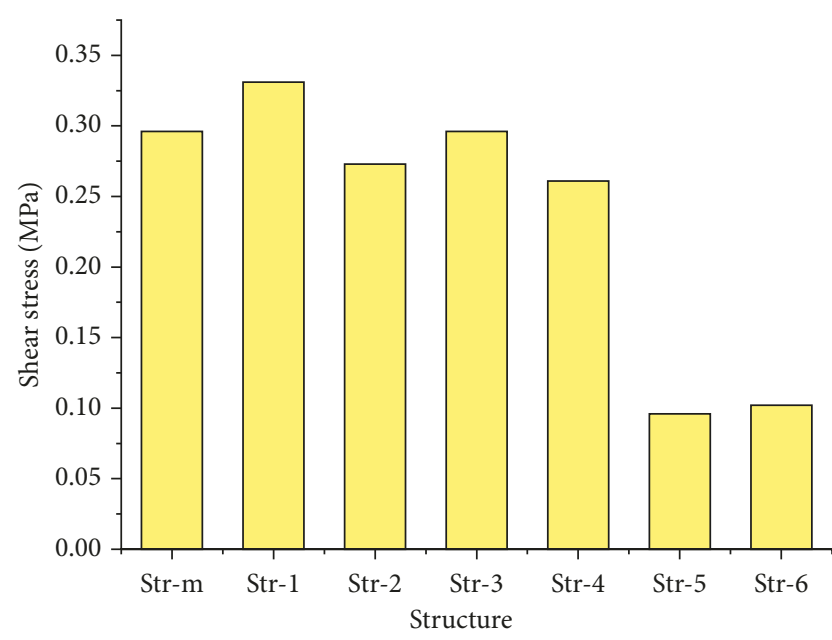

Figure 16: Maximum shear stresses of asphalt courses.

depth. Second, the thickness of the asphalt course of Str-4 was relative thinner, and its mechanical behavior was probably similar to that of structures using only chemicaltreated bases, resulting in the maximum shear stresses of Str4, Str-m, Str-1, and Str-2 close to each other. Besides, in spite of the same depth of asphalt courses in Str-5 and Str-6, the rutting depth of Str-6 (4.55 mm) was higher than that of Str$5(4.416 \mathrm{~mm})$, probably because the combination of base and subbase in Str-5 was better than that of Str-6. Superficially, the adaptability of Str- 4 was better than that of Str-5 and Str6. However, reasons for rutting in practice were complicated, and they cannot be entirely considered in the simulation. Nevertheless, one of the most important reasons for rutting was the insufficient shear resistance. In this case, it was more reasonable to determine the adaptability through shear stresses. Therefore, due to smaller maximum shear stresses, Str- 5 and Str- 6 were better than Str- 4 .

Due to four asphalt courses in Str-3 including a flexible base, compared with other structures which used chemicaltreated bases, there is a viewpoint in the long term in China that one of the disadvantages of an asphalt pavement with a flexible base is the poor ability on deformation resistance. However, through the simulation, it was found that the rutting depth of Str-3 was lower than that of Str-1, which had a chemical-treated base. Therefore, it could be concluded that when the composition of the surface course, base, and subbase was proper and reasonable, it is possible that pavement using a flexible base could also have a good performance over rutting resistance.

In summary, according to rutting depths and the maximum shear stresses of asphalt courses under coupling effects of traffic loads and high temperatures, the adaptability of seven pavement structures decreased in the following order: Str-5 $>$ Str- $6>$ Str $-4>$ Str-2 $>$ Str-3 $>$ Str-m $>$ Str -1 .

7.2.2. Deflection on the Pavement Surface. The simulation results of deflection on the pavement surface are shown in Figure 17.

From Figure 17, it was observed that the deflection of the pavement using a flexible base was the highest, that is, Str-3. For example, the deflection of Str-3 was 3.26 times higher than that of Str-5 and 1.22 times higher than that of Str-1. Hence, under the climate experiencing high temperatures and significant temperature differences, pavements using compound bases were the most stable. It is possible that, under the effects of haversine traffic loads, the dissipation of forces was primarily depending on the absorption of the structure itself and the reflection of the subjacent layer. Because the rigidity of chemical-treated bases was better than that of flexible bases, their dissipation of forces mainly relied on the reflection. Hence, under the impact of traffic loads, deformation of pavements that only used chemicaltreated bases primarily occurred on the asphalt surface course. As for the pavement using a flexible base, it could not reflect the impact of traffic loads as good as pavements using chemical-treated bases, which resulted in that the dissipation of forces was mainly depending on the absorption of the structure itself. Therefore, deformation of the whole structure was relatively higher. Moreover, pavements using both chemical-treated bases and flexible bases had the characteristics of the two categories of pavements mentioned before, that is, the capacity for both absorption and reflection. Therefore, the deformation responses were sluggish.

Despite the same form of base courses of Str-4, Str-5, and Str-6, that is, compound bases of chemical-treated bases and flexible bases, the deflection of Str-4 was significantly different from that of Str-5 and Str-6; however, it was close to that of Str-m, Str-1, and Str-2, which had only chemicaltreated bases. The reason for that was possibly the relatively thin asphalt course, which is $22 \mathrm{~cm}$. In this case, the reflection of chemical-treated bases was highlighted, and the absorption of flexible bases was weakened, which impaired the advantage of pavements using compound bases and resulted in a larger deflection of Str-4.

Moreover, Str- 4 and Str-2 shared the same thickness of chemical-treated bases; however, the deflection of Str- 4 was smaller than that of Str-2. Hence, it could be deduced that increasing the thickness of asphalt courses would help with the integration of pavement and decrease the deflection on 


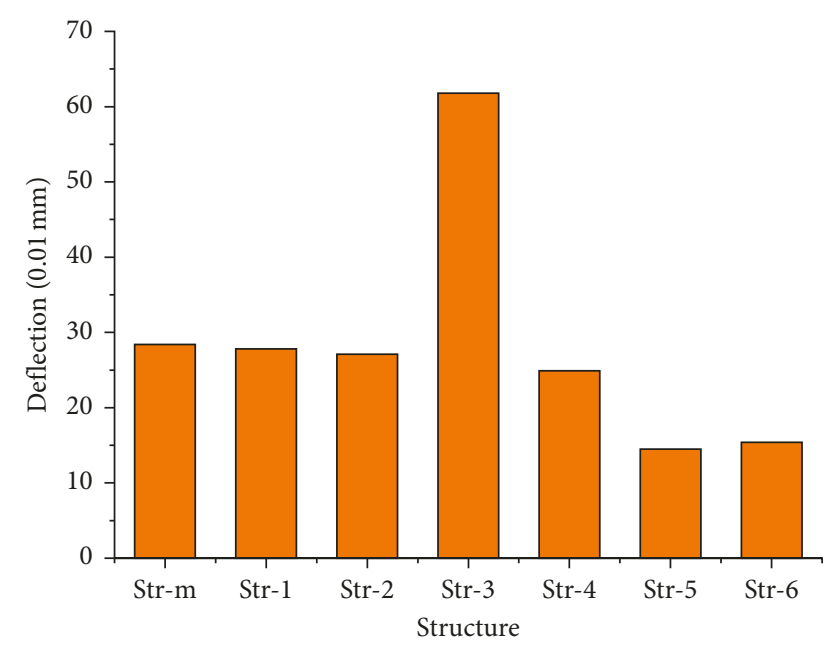

FIGURE 17: Deflections on the pavement surface of seven pavement structures.

the pavement surface. In addition, to make a comparison between Str-5 and Str-6, it was found that the deflection of Str-5 was smaller. Hence, under the condition that the thickness of the asphalt course was the same, increasing the thickness of chemical-treated bases would also help with deformation resistance.

In conclusion, according to deflection on the pavement surface, the adaptability of seven pavement structures decreased in the following order: Str-5 $>$ Str-6 $>$ Str- $4>$ Str$2>$ Str-m $>$ Str-1 $>$ Str-3.

7.2.3. Subgrade Top Surface Strain. The simulation results of compressive strains at the subgrade top surface of seven pavement structures are shown in Figure 18.

From Figure 18, it was found that the compressive strain at the subgrade top surface of Str-3 was the largest and significantly different from that of the other pavement structures. Moreover, compressive strains at the subgrade top surface of pavements using compound bases were the smallest. For example, the compressive strain of Str-3 was 7.20 times higher than that of Str-4. Hence, it suggests that pavements using flexible bases may not be appropriate for the condition of high temperatures and significant temperature differences. It is possible that chemical-treated bases of the other six structures were effective in bearing traffic loads and weakening the impact of dynamic loads. Moreover, through the comparison among structures except Str-3, it was observed that increasing the thickness of asphalt courses properly could effectively reduce influences on the subgrade. It could be illustrated clearly by the compressive strains of Str-2 and Str-4.

From Figure 18, it was also found that when the thickness of the asphalt course was guaranteed, increasing the thickness of the chemical-treated base could enhance the ability on deformation resistance under climates experiencing high temperatures and significant temperature differences. For example, Str-5 and Str-6, their compressive strains at the subgrade top surface were $59.9 \mu \varepsilon$ and $60.9 \mu \varepsilon$,

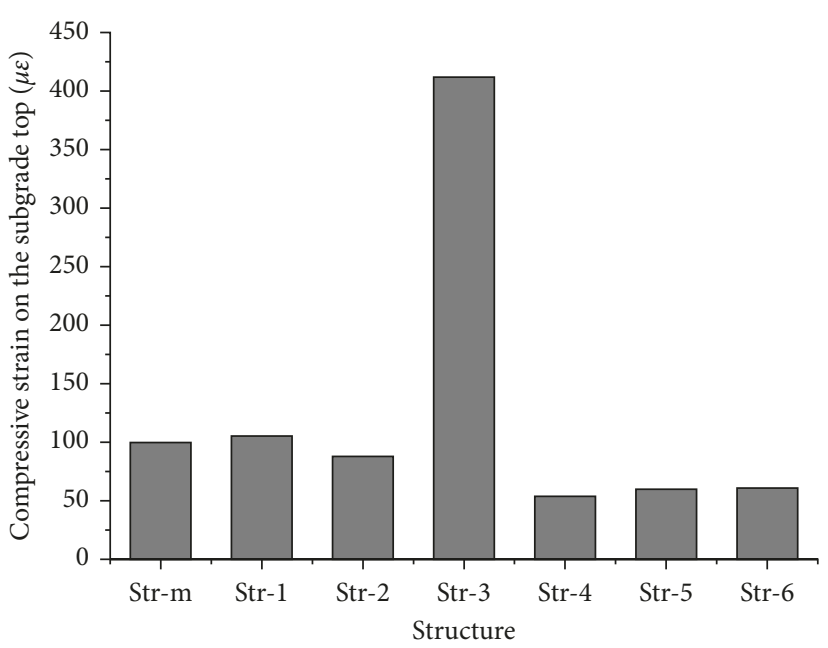

FIGURE 18: Compressive strains at the subgrade top surface of seven pavement structures.

respectively. Their forms of asphalt courses were equivalent, while the chemical-treated base of Str- 5 was thicker than that of Str-6.

In addition, since compressive strains at the subgrade top surface of pavements using compound bases were the smallest, it probably suggested that this kind of pavement structures had the highest adaptability to high temperatures and significant temperature differences.

In summary, according to compressive strains at the subgrade top surface of these structures, the adaptability of seven pavements decreased in the following order: Str$4>$ Str- $5>$ Str- $6>$ Str- $2>$ Str-m $>$ Str- $1>$ Str- 3 .

\section{Conclusion}

In this paper, to analyze the adaptability of pavement structures to climates experiencing high temperatures and significant temperature differences in southern Xinjiang, the FE method was used. Temperature fields and mechanical responses under this condition were simulated. The following observations were made through the simulation results:

(1) With the increase of pavement depths, the influence of air temperature weakened obviously, and the variations of structure temperatures and air temperatures exhibited a time lag. Besides, the influence of air temperature had the greatest impact on Str-1, possibly due to the thinnest asphalt course. Although the temperature field was different among seven structures, when the depth was up to $60 \mathrm{~cm}$, there were no distinct differences, which means that the selection of the pavement structure form has little influence on the temperature of the subgrade.

(2) In seven pavement structures, according to the rutting and compressive strains at the subgrade top surface, Str-4 was the most adaptable structure; according to the maximum shear stress of asphalt courses and deflection on the pavement surface, Str-5 was more 
appropriate. In conclusion, the adaptability of seven pavements to high temperatures and significant temperature differences in southern Xinjiang decreased in the following order: Str-5 $>$ Str- $6>$ Str$4>$ Str-2 $>$ Str-m $>$ Str- $1>$ Str-3.

(3) Pavements using compound bases had obvious advantages over the other two categories of pavements, when the deformation resistance was taken into consideration in the analysis of the adaptability to southern Xinjiang. It is possible that relatively thicker asphalt courses had positive effects on the absorption of dynamic loads. Moreover, the chemical-treated bases were effective in bearing traffic loads and weakening the influence of impact loads on the structure deformation.

\section{Data Availability}

Data in Tables 5 and 6 are available at https://www. tandfonline.com/doi/abs/10.1080/10298436.2018.1435883? journalCode=gpav20.

\section{Conflicts of Interest}

The authors declare that they have no conflicts of interest.

\section{Authors' Contributions}

Xueying Zhao and Baofu Ma conceived and designed the simulation. Xueying Zhao performed the simulation. Xueying Zhao and Baofu Ma analyzed the data. Aiqin Shen contributed analysis and simulation tools. Xueying Zhao wrote the paper.

\section{Acknowledgments}

This research is supported by the Xinjiang Communications Construction Administrative Bureau and Xinjiang Academy of Transportation Sciences.

\section{References}

[1] Z. Zhao and H. Xu, "The research of temperature variation trends over Xinjiang in China by extreme-point symmetric mode decomposition method," Geographical Research, vol. 12, pp. 2358-2366, 2014.

[2] Z. Yan, "Analysis of the temperature field in layered pavement system," Journal of Tongji University, vol. 3, pp. 76-85, 1984.

[3] E. S. Barber, Calculation of Maximum Pavement Temperatures from Weather Reports, Highway Research Board Bulletin, Washington, DC, USA, 1957.

[4] J. T. Christison and K. O. Anderson, "The response of asphalt pavements to low temperature climatic environments," in Proceedings of the International Conference on the Structural Design of Asphalt Pavements, London, UK, 1972.

[5] R. L. Lytton, An Integrated Model of the Climatic Effects on Pavements: Final Report, Federal Highway Administration, Frost, MN, USA, 1993.

[6] R. H. Williamson, "Effects of environment on pavement temperatures," in Proceedings of the International Conference on Structural Design, London, UK, 1972.
[7] J. A. D'Angelo, "The relationship of the MSCR test to rutting," Road Materials and Pavement Design, vol. 10, no. 1, pp. 61-80, 2009.

[8] J. D’Angelo, R. Kluttz, R. N. Dongre, and L. Zanzotto, "Revision of the Superpave high temperature binder specification: the multiple stress creep recovery test," Asphalt Paving Technology: Association of Asphalt Paving TechnologistsProceedings of the Technical Sessions, vol. 76, no. 2, pp. 123$162,2007$.

[9] A. Shenoy, "Refinement of the Superpave specification parameter for performance grading of asphalt," Journal of Transportation Engineering, vol. 127, no. 5, pp. 357-362, 2001.

[10] A. Subhy, "Advanced analytical techniques in fatigue and rutting related characterisations of modified bitumen: literature review," Construction and Building Materials, vol. 156, pp. 28-45, 2017.

[11] B. Diefenderfer and I. Alqadi, "Development and validation of a model to predict pavement temperature profile," in Proceedings of the Transportation Research Board 82nd Annual Meeting, Washington, DC, USA, 2003

[12] Å. Hermansson, "Simulation model for calculating pavement temperatures including maximum temperature," Transportation Research Record: Journal of the Transportation Research Board, vol. 1699, no. 1, pp. 134-141, 2000.

[13] D. Y. Park, N. Buch, and K. Chatti, "Effective layer temperature prediction model and temperature correction via falling weight deflectometer deflections," Transportation Research Record: Journal of the Transportation Research Board, vol. 1764, no. 1, pp. 97-111, 2001.

[14] D. S. Gedafa, M. Hossain, and S. A. Romanoschi, "Perpetual pavement temperature prediction model," Road Materials and Pavement Design, vol. 15, no. 1, pp. 55-65, 2014.

[15] H.-C. Dan, L.-H. He, L.-H. Zhao, and J.-Q. Chen, “Coupled hydro-mechanical response of saturated asphalt pavement under moving traffic load," International Journal of Pavement Engineering, vol. 16, no. 2, pp. 125-143, 2015.

[16] H. Kassem, G. Chehab, and G. Saad, "An FEM-predictive tool for simulating the cooling characteristics of freshly paved asphalt concrete layers," International Journal of Pavement Engineering, vol. 16, no. 2, pp. 157-167, 2015.

[17] A. Mammeri, L. Ulmet, C. Petit, and A. M. Mokhtari, "Temperature modelling in pavements: the effect of long- and short-wave radiation," International Journal of Pavement Engineering, vol. 16, no. 3, pp. 198-213, 2015.

[18] W. Si, N. Li, B. Ma, Y.-x. Tian, and X.-y. Zhou, "Temperature response to tensile characteristics of the hot asphalt mixtures," KSCE Journal of Civil Engineering, vol. 20, no. 4, pp. 13361346, 2016.

[19] J. F. Wang, X. Wu, X.-1. Fan, and Y.-r. Chen, "Stress-strain model of cement asphalt mortar subjected to temperature and loading rate," Construction and Building Materials, vol. 111, pp. 164-174, 2016.

[20] H. Wang, Z. You, J. Mills-Beale, and P. Hao, "Laboratory evaluation on high temperature viscosity and low temperature stiffness of asphalt binder with high percent scrap tire rubber," Construction and Building Materials, vol. 26, no. 1, pp. 583590, 2012.

[21] N. Dong, C. Li, and F. Ni, "Modeling and analysis of stressdependency coupling with temperature-sensitivity for surface layer of semi-rigid base asphalt pavement," in Proceedings of the Airfield and Highway Pavements, Miami, FL, USA, June 2015.

[22] W. Xue, E. Weaver, L. Wang, and Y. Wang, "Influence of tyre inflation pressure on measured pavement strain responses 
and predicted distresses," Road Materials and Pavement Design, vol. 17, no. 2, pp. 328-344, 2016.

[23] H. Guo and S. Chen, "Numerical analysis of temperature-load coupling stress for asphalt pavement," Journal of Chang'an University (Natural Science Edition), vol. 2, pp. 15-19, 2010.

[24] X Hu, Dynamic Response Analysis of Asphalt Pavement in Stress-Temperature United Field, Shijiazhuang Tiedao University, Shijiazhuang, China, 2015.

[25] Y. Liu, "Estimation and seasonal variation of solar radiation in Xinjiang based on a multi-sensor data approach," Journal of Arid Land Resources and Environment, vol. 3, pp. 161-165, 2015.

[26] X. Dai, P. Wang, and K. Zhang, "A study on precipitation trend and fluctuation mechanism in northwestern China over the past 60 years," Acta Physica Sinica, vol. 12, pp. 527-537, 2013.

[27] Y. Xin, "Climate division of seasonal precipitation and their changing trend in Xinjiang," Journal of Desert Research, vol. 5, pp. 948-959, 2009.

[28] Y. Qin and J. E. Hiller, "Modeling temperature distribution in rigid pavement slabs: impact of air temperature," Construction and Building Materials, vol. 25, no. 9, pp. 3753-3761, 2011.

[29] M. Solaimanian and T. W. Kennedy, "Predicting maximum pavement surface temperature using maximum air temperature and hourly solar radiation," Journal of Fruit and Ornamental Plant Research, vol. 103, no. 7, 1993.

[30] Y. Xin, "Homogeneity adjustment of annual mean wind speed and elementary calculation of fundamental wind pressure over Xinjiang meteorological stations," Climatic and Environmental Research, vol. 2, pp. 184-196, 2012.

[31] Q. Li, The Study on the Highway Roadbed Temperature and Humidity Variation Characteristics and Mechanical Properties in Xinjiang, Chang'an University, Xi'an, China, 2012.

[32] H. Tang, Research on Temperature and Salt Migration Law of Sulphate Salty Soil Subgrade in Xinjiang Region, Beijing Jiaotong University, Beijing, China, 2012.

[33] J. Liu, "Solar radiation character and solar energy resource in Xinjiang," Arid Meteorology, vol. 4, pp. 61-66, 2008.

[34] L. Li, Research on Rutting in the Section of Steep Longitudinal Slope of Mountainous Expressway, Southeast University, Nanjing, China, 2013.

[35] Z. Zheng, Study on Adaptability of Fiber Reinforced Chip Seal in Hot-Moist Region of South China, Chang'an University, Xi'an, China, 2013.

[36] L. Wang, Study on Xinjiang Mountain Road Vehicle Traveling Speed Control System-The Establishment of Prediction Model of Vehicle Speed, Xinjiang Agricultural University, Ürümqi, China, 2015.

[37] L. Huang and C. Sheng, "Relationship between vehicle dynamic amplification factor and pavement roughness," Journal of Highway and Transportation Research and Development, vol. 3, pp. 27-30, 2006.

[38] J. Kim, G. A. Sholar, and S. Kim, "Determination of accurate creep compliance and relaxation modulus at a single temperature for viscoelastic solids," Journal of Materials in Civil Engineering, vol. 20, no. 2, pp. 147-156, 2008.

[39] C. H. Ho and P. Romero, "Alternative function to represent relaxation modulus of viscoelastic materials," Journal of Materials in Civil Engineering, vol. 24, no. 2, pp. 152-158, 2015.

[40] Y. Zhao, L. Jiang, and L. Zhou, "Ambient temperature and vehicle loading effects on asphalt concrete pavement rutting development," in Proceedings of the Fifth International Conference on Transportation Engineering (ICTE 2015),
P. Qiyuan, Ed., pp. 1084-1091, American Society of Civil Engineers, Dalian, China, 2015.

[41] J. Zhang, L. Xu, and B. Wang, "Modification of creep model of asphalt mixture and parameters determination," Journal of Wuhan University of Technology (Transportation Science and Engineering), vol. 4, pp. 699-702, 2010.

[42] J. Zheng, S. Lv, and X. Tian, "Research on viscoelastic parameters of bituminous mixtures and their applications," Journal of Zhengzhou University (Engineering Science), vol. 4, pp. 8-11, 2004.

[43] X. Zhao, A. Shen, and B. Ma, "Temperature response of asphalt pavement to low temperatures and large temperature differences," International Journal of Pavement Engineering, pp. 1-14, 2018. 


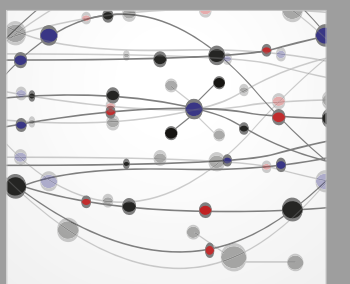

The Scientific World Journal
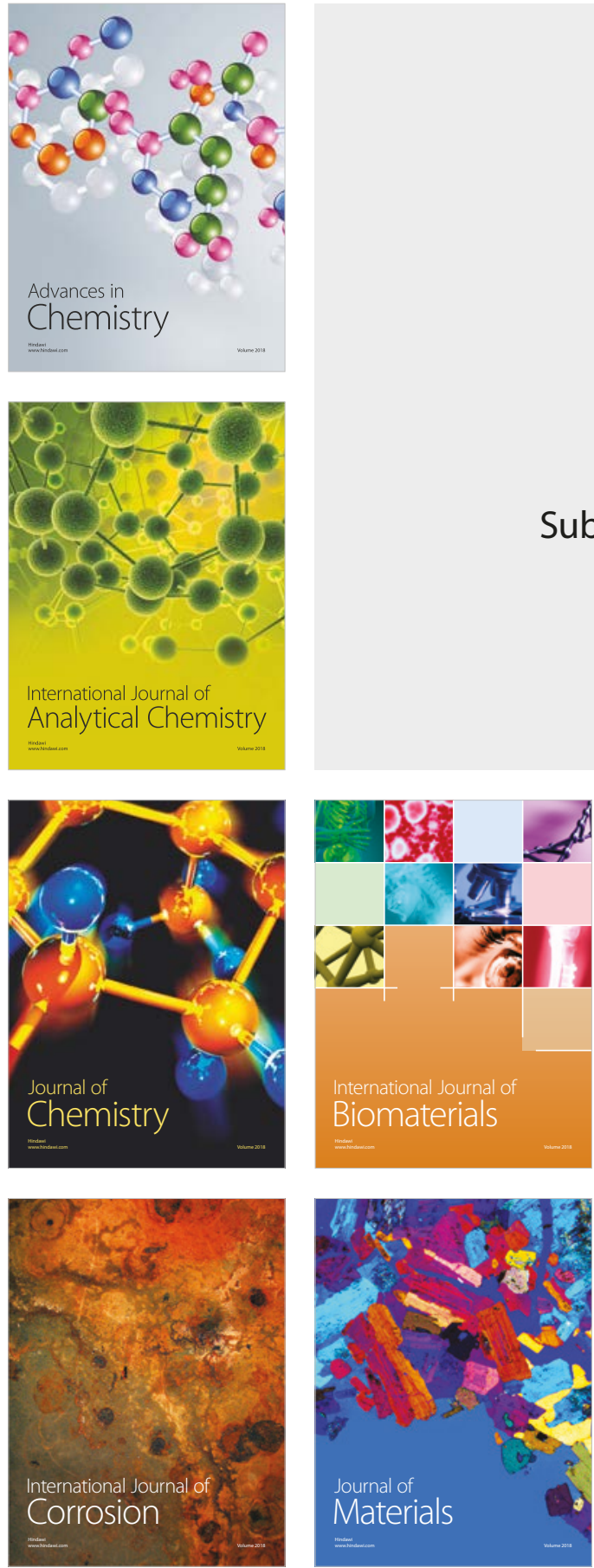

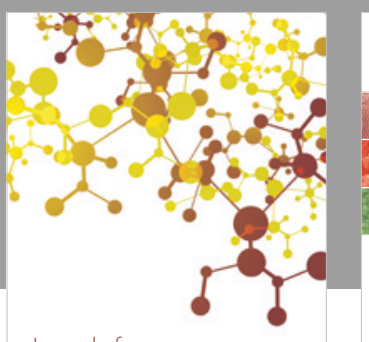

Journal of

Applied Chemistry
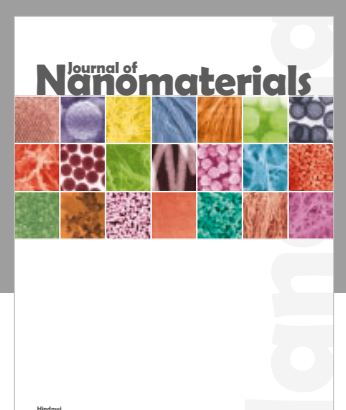

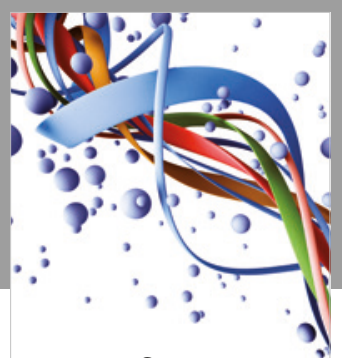

Scientifica

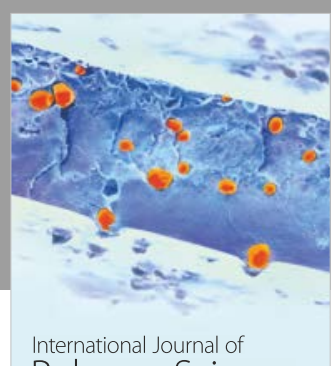

Polymer Science

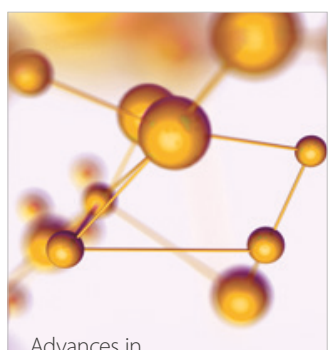

Physical Chemistry
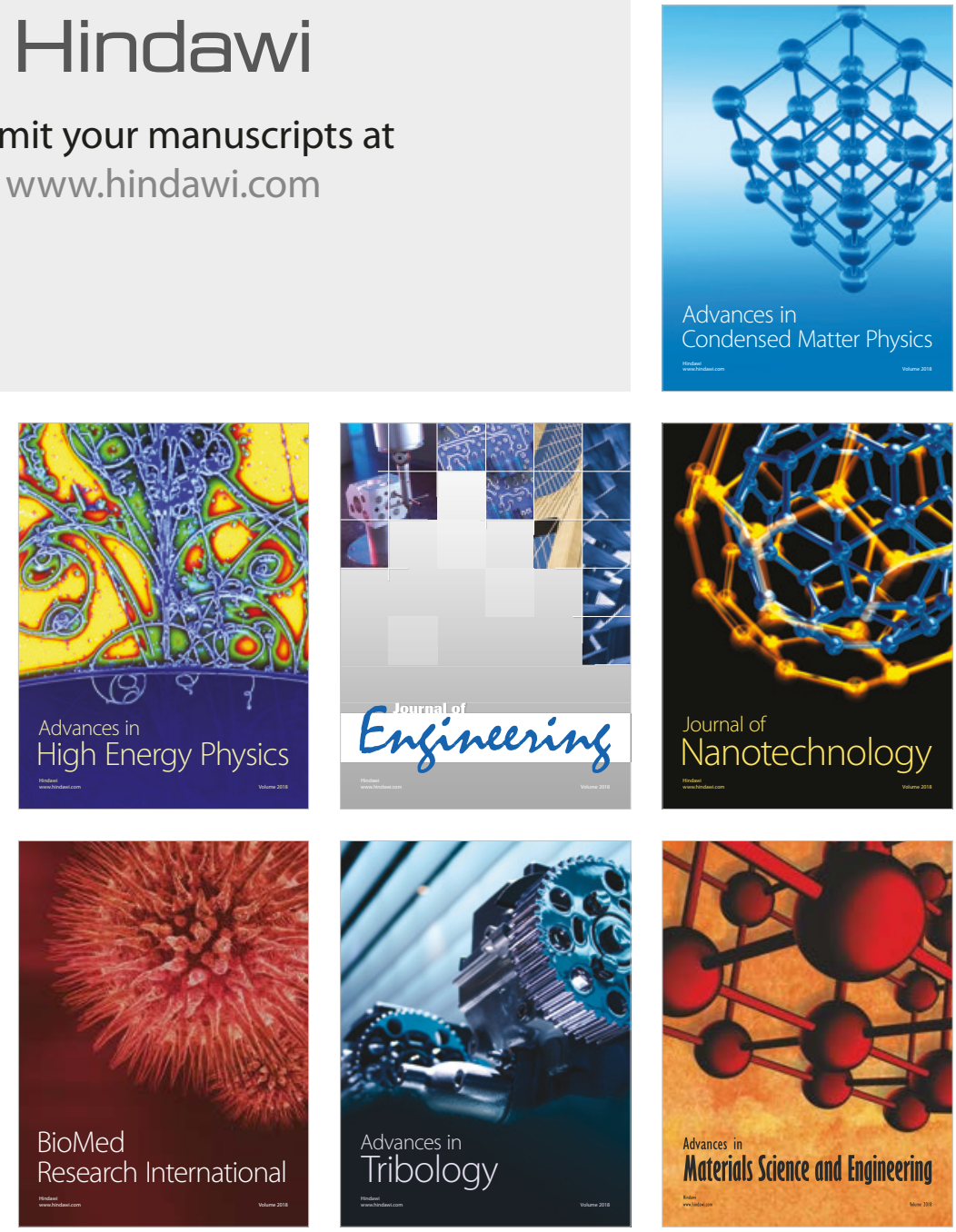